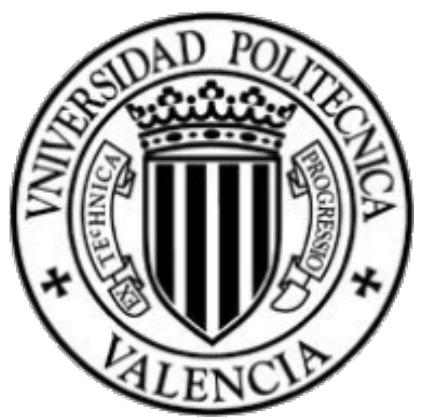

Universitat Politècnica de València

Departament de Matemàtica Aplicada

PhD. THESIS

\title{
Modelling with uncertainty the ideological evolution of a society with extreme groups
}

\author{
Ph.D. CANDIDATE \\ ADVISORS \\ Dr. Francisco José Santonja Gómez \\ Ana Celia Tarazona Tornero \\ Dr. Rafael Jacinto Villanueva Micó \\ Dr. Francisco Javier Villanueva Oller
}

Valencia - February 2014 
Dr. Francisco José Santonja Gómez, professor at the Universitat de València, Rafael Jacinto Villanueva Micó, professor at the Universitat Politècnica de València and Dr. Francisco Javier Villanueva Oller professor at the Centro de Estudios Superiores Felipe II,

CERTIFY that the present thesis entitled Modelling with uncertainty the ideological evolution of a society with extreme groups has been performed under our supervision in the Department of Applied Mathematics at the Universitat Politècnica de València by Ana Celia Tarazona Tornero. It constitutes her thesis dissertation to obtain the $\mathrm{PhD}$ degree in Mathematics.

In compliance with the current legislation, we authorize the presentation of this dissertation signing the present certificate.

Valencia, January 17, 2014

Francisco José

Santonja Gómez
Rafael Jacinto

Villanueva Micó
Francisco Javier

Villanueva Oller 


\section{Resumen en Español}

El País Vasco es una región (Comunidad Autónoma) situada en el norte de España donde, desde los años 60, existe una organización llamada ETA que quiere alcanzar sus objetivos políticos mediante medios violentos. La población vasca está dividida, principalmente, entre los que apoyan o rechazan los objetivos políticos de ETA y sus medios violentos. Además, la presión de ETA y de los grupos que la apoyan sobre la población vasca, está presente en la vida cotidiana.

Teniendo en cuenta la situación vasca, en esta tesis doctoral estamos interesados en cómo los diferentes grupos definidos por su actitud hacia ETA evolucionan con el tiempo, fijándonos especialmente en dos aspectos:

- averiguar cuales son los eventos más relevantes que influyen en los cambios de la evolución sobre la actitud hacia ETA,

- teniendo en cuenta la relación entre los grupos que apoyan a ETA y la fuente de sus activistas, predecir la evolución de la actitud hacia ETA en el futuro próximo para saber si el número de miembros de los grupos que apoyan a ETA disminuyen y, como consecuencia, ETA también.

Para conseguirlo, por una parte, utilizaremos datos electorales y del Euskobarómetro (el Euskobarómetro es una encuesta sociológica realizada en el País Vasco), y así, construiremos modelos matemáticos asumiendo como hipótesis que el cambio de actitud, ideología u opinión puede ser socialmente transmitido. Por tanto, podremos utilizar técnicas clásicas de epidemiología para la construcción y estudio de dichos modelos.

Por otra parte, no debemos olvidar que queremos estudiar un problema del área de las Ciencias Sociales donde los datos provienen de encuestas, con lo que contienen un error y una incertidumbre inherentes. Así pues, durante el desarrollo de esta memoria se hará necesario utilizar técnicas para tratar la incertidumbre en los modelos que iremos presentando. De hecho, en cada nueva técnica que usemos, intentaremos evitar los inconvenientes que aparecían en la técnica anterior. 
La estructura de esta memoria es la siguiente. En el capítulo 1 introduciremos el problema a estudiar y haremos un repaso histórico del trabajo realizado.

En el capítulo 2, resumiremos los hechos más importantes en la historia de ETA que consideramos relevantes para el adecuado desarrollo de la presente tesis.

Presentaremos un primer modelo en el capítulo 3. En él, dividiremos la población vasca dependiendo del partido político al que votan y luego clasificaremos los partidos políticos respecto a su opinión sobre la idea "independencia de España", uno de los principales objetivos de ETA. De esta forma, utilizando datos de las elecciones generales al Parlamento Español, construiremos un modelo de tipo epidemiológico y usaremos la técnica del Muestreo del Hipercubo Latino para predecir con incertidumbre en futuras fechas electorales, la dinámica de la población vasca respecto de la idea "independencia de España".

En el capítulo 4, utilizamos datos del Euskobarómetro sobre "la actitud de la población hacia ETA" para construir un modelo que nos permita averiguar si la "Ley de Partidos Políticos" (LPP) aprobada en junio de 2002 tuvo algún efecto sobre la actitud de los vascos hacia ETA. Aplicaremos una técnica llamada "bootstrapping" para saber si la diferencia entre la predicción de modelo y los datos del Euskobarómetro tras la LPP es significativa y cuantificar dicha diferencia. En este caso, la técnica de bootstrapping es la que nos permitirá estudiar la incertidumbre.

Finalmente, en el capítulo 5, utilizando el mismo modelo que en el capítulo 4 y datos del Euskobarómetro referentes a la actitud de la población hacia ETA desde mayo de 2005, predeciremos con incertidumbre la dinámica de evolución de los diferentes grupos mediante una banda de confianza del modelo en los próximos años. Esto lo conseguiremos introduciendo una nueva técnica computacional para tratar la incertidumbre en el modelo. 


\section{Resum en Valencià}

El País Basc és una regió (Comunitat Autònoma) situada al nord d'Espanya on, des dels anys 60, hi ha una organització anomenada ETA que vol aconseguir els seus objectius polítics per mitjans violents. La població basca està dividida, principalment, entre els que recolzen o rebutgen els objectius polítics d'ETA i els seus mitjans violents. A més, la pressió d'ETA i dels grups que la recolzen sobre la població basca, estan presents en la vida quotidiana.

Tenint en compte la situació basca, en esta tesi doctoral estem interessats en com els diferents grups definits per la seua actitud cap a ETA evolucionen amb el temps, fixant-nos especialment en dos aspectes:

- esbrinar quals són els esdeveniments més rellevants que influïxen en els canvis de l'evolució sobre l'actitud cap a ETA,

- tenint en compte la relació entre els grups que recolzen a ETA i la font dels seus activistes, predir l'evolució de l'actitud cap a ETA en el futur pròxim per a saber si el nombre de membres dels grups que recolzen a ETA disminuïxen i, com a conseqüència, ETA també.

Per a aconseguir-ho, d'una banda, utilitzarem dades electorals i de l'Euskobarómetro (l'Euskobarómetro és una enquesta sociològica realitzada en el País Basc), i així, construirem models matemàtics assumint com a hipòtesi que el canvi d'actitud, ideologia o opinió pot ser socialment transmés. Per tant, podrem utilitzar tècniques clàssiques d'epidemiologia per a la construcció dels anomenats models.

D'altra banda, no hem d'oblidar que volem estudiar un problema de l'àrea de les Ciències Socials on les dades provenen d'enquestes, amb la qual cosa contenen un error i una incertesa inherents. Així, durant el desenrotllament d'esta memòria es farà necessari utilitzar tècniques per a tractar la incertesa en els models que anirem presentant. De fet, en cada nova tècnica que usem, intentarem evitar els inconvenients que apareixien en la tècnica anterior.

L'estructura d'esta memòria és la següent. En el capítol 1 introduirem el problema a estudiar i farem un repàs històric del treball realitzat. 
En el capítol 2, resumirem els fets més importants en la història d'ETA que considerem rellevants per a l'adequat desenrotllament de la present tesi.

Presentarem un primer model en el capítol 3. En ell, dividirem la població basca depenent del partit polític a què voten i després classificarem els partits polítics respecte a la seua opinió sobre la idea "independència d'Espanya", un dels principals objectius d'ETA. D'esta manera, utilitzant dades de les eleccions generals al Parlament Espanyol, construirem un model de tipus epidemiològic i usarem la tècnica de l'Hipercub Llatí per a predir amb incertesa en futures dates electorals, la dinàmica de la població basca respecte de la idea "independència d'Espanya".

En el capítol 4, utilitzem dades de l'Euskobarómetro sobre "l'actitud de la població cap a ETA" per a construir un model que ens permeta esbrinar si la "Llei de Partits Polítics" (LPP) aprovada al juny de 2002 va tindre algun efecte sobre l'actitud dels bascos cap a ETA. Aplicarem una tècnica anomenada "bootstrapping" per a saber si la diferència entre la predicció del model i les dades de l'Euskobarómetro després de la LPP és significativa i quantificar eixa diferència. En este cas, la tècnica de bootstrapping és la que ens permetrà estudiar la incertesa.

Finalment, en el capítol 5, utilitzant el mateix model que en el capítol 4 i dades de l'Euskobarómetro referents a l'actitud de la població cap a ETA des de maig de 2005, predirem amb incertesa la dinàmica d'evolució dels diferents grups per mitjà d'una banda de confiança del model en els pròxims anys. Per a fer açò, introduirem una nova tècnica computacional per a tractar la incertesa en el model. 


\section{Abstract in English}

The Basque Country is a northern Spanish region (Autonomous Community) where, from 1960's, there is a organization called ETA that wants to achieve its political goals by violent means. The Basque population is divided, mainly, into the ones who support or reject the ETA's political goals and its violent means. Also, the pressure of ETA and its supporters on the Basque population are present in the daily life.

Taking into account the Basque scenario, in this $\mathrm{PhD}$ dissertation, we are interested in how the different groups of people defined by their attitude towards ETA evolve over the time, with two main aims:

- find out which the most relevant events that make changes in the attitude evolution are,

- taking into account the relation between ETA's supporters and ETA's member source, predict the attitude evolution in the next future in order to see if the supporters group wanes and, as a consequence, ETA also does.

To do that, on one hand, we use elections and Euskobarometro data (Euskobaromero is a sociological statistical survey in the Basque Country), and then, we build the mathematical models assuming the hypothesis that the change of attitude, ideology or opinion may be socially transmitted. Therefore, classical techniques in epidemiology are used to build and study these models.

On the other hand, we should not forget that we want to study a problem in Social Sciences, where data, coming from surveys, contain errors. Therefore, during the development of this dissertation it is necessary to use techniques to deal with uncertainty in the presented models. In fact, we use some, trying to avoid in each new technique the disadvantages that appear in the previous one.

The structure of this $\mathrm{PhD}$ dissertation is as follows. In Chapter 1 we introduce the problem to be studied and make a historical overview of the $\mathrm{PhD}$ thesis. 
In Chapter 2 we summarise the main facts in the history of ETA that we consider relevant to the proper development of the present dissertation.

A first model is presented in Chapter 3. Here, we divide the population of the Basque Country depending on the political party they vote and classify the political parties respect to their opinion on the idea of "independence from Spain", one of the main goals of ETA. Thus, with data of general elections, we build a type-epidemiological model and use the Latin Hypercube Sampling technique to predict with uncertainty over the next election dates, the dynamics of the population respect to the idea of "independence from Spain".

In the Chapter 4, Euskobarometro data about the "population attitude towards ETA" are used to build a model to find out if the "Law of Political Parties" (LPP) passed in Jun 2002 had effect on the attitude towards ETA of the Basque Population. We use a bootstrapping technique to know if the differences between the model prediction and Euskobarometro data after LPP are significative and quantify these differences. In this case, bootstrapping is the technique that allows us to deal with the model uncertainty.

In the Chapter 5, using the same model as in the Chapter 4 and Euskobarometro data about the population attitude towards ETA since May 2005, we predict with uncertainty the evolution dynamics of the groups providing a model confidence band prediction over the next few years. To do that we introduce a new computational technique to deal with the model uncertainty. 


\section{Contents}

1 Introduction $\quad 16$

1.1 Uncertainty . . . . . . . . . . . . . . . . . 18

1.2 Overview of the dissertation . . . . . . . . . . . 20

2 Euskadi Ta Askatasuna (ETA) 25

2.1 Euskobarometro and the attitude of the Basque population towards ETA . . . . . . . . . . . . . 26

2.2 Current situation . . . . . . . . . . . . . . . . 28

3 A first mathematical model of the evolution of the Basque Country population respect to their opinion about ETA un$\begin{array}{ll}\text { der its pressure } & 31\end{array}$

3.1 Classification of ideological groups . . . . . . . . . . . . . . 32

3.2 Building the type-epidemiological mathematical model . . . . 35

3.3 Scaling the model $(3.1)-(3.5) \ldots \ldots . \ldots 38$

3.4 Model fitting . . . . . . . . . . . . . . . . . . . . . . 39

3.5 Trends over next few years . . . . . . . . . . . . . . . . . . . . . . . . . . . . . .

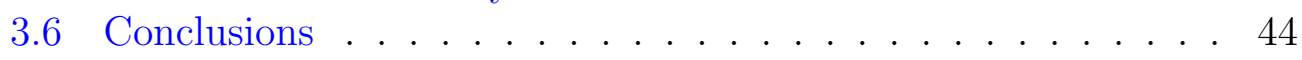

4 The effect of the Spanish Law of Political Parties (LPP) on the attitude of the Basque Country population towards ETA 46

4.1 Data . . . . . . . . . . . . . . . . 47

4.2 Model building . . . . . . . . . . . . . . . . . . . . . . . 49

4.3 Estimation of model parameters . . . . . . . . . . . . . 51

4.4 Analysis of the effect of the LPP . . . . . . . . . . . . . . 51

4.4.1 Finding out if the differences between the data and the model prediction are (or are not) due to the effect of the LPP on the Basque population? . . . . . . . . . . . 52

4.4.2 Error term analysis . . . . . . . . . . . . 53

4.4.3 Generating new perturbed data . . . . . . . . . 54

4.4.4 Obtaining confidence intervals for model outputs . . . 55 
4.5 Conclusion . . . . . . . . . . . . . . . . . . 57

5 A probabilistic estimation and prediction technique for the evolution of the attitude of the Basque Country population towards ETA $\quad 59$

5.1 Data and model . . . . . . . . . . . . . . . . 60

5.2 Probabilistic estimation: A computational technique to determine the empirical probabilistic distribution of model parameters .......................... 61

5.2 .1 Data . . . . . . . . . . . . . 62

5.2 .2 Probabilistic estimation . . . . . . . . . 62

5.2.3 Probabilistic estimation analysis . . . . . . . . 66

5.3 Probabilistic predictions over the next four years . . . . . . . 68

5.3.1 Robustness of the presented method . . . . . . . 69

5.4 Conclusion . . . . . . . . . . . . . . . . . . 70

6 Conclusion $\quad 72$ 


\section{List of Figures}

1.1 Percentage of Basque people concerned about violence and terrorism over the time since May 2000 until May 2013 [33]. . 18

1.2 (Up) Percentage of Basque people depending on their freedom feeling to talk about politics. (Down) Percentage of Basque people depending on their fear feeling to participate actively in politics. [33]. . . . . . . . . . . . . . . . 19

2.1 Percentage of Basque Country population with an attitude of support towards ETA since May 1995 until Nov 2012. Vertical lines correspond to remarkable dates. . . . . . . . . . . . . 27

2.2 Percentage of Basque Country population with an attitude of rejection towards ETA since May 1995 until Nov 2012. Vertical lines correspond to remarkable dates. . . . . . . . . . . . 28

2.3 Percentage of Basque Country population with an attitude of indifference/abstention towards ETA since May 1995 until Nov 2012. Vertical lines correspond to remarkable dates. . . . 29

3.1 Correspondence analysis shows three different profiles, nationalist parties, right-wing and center parties, and left-wing parties with ambiguous positions respect to independence and the use of violence. . . . . . . . . . . . . . . . . 33

3.2 This figure shows the percentage of votes of each subpopulation in each election. Vertical lines correspond to electoral days. Let us consider in our study data between 1979 and 1996, where most of the time the Socialist Party (PSOE) was in the government, and the same policy against terrorism can be assumed. . . . . . . . . . . . . . . . 35

3.3 Diagram corresponding to the model defined by the system of differential equations $(3.1)-(3.5) \ldots \ldots . \ldots 37$

3.4 Immigration and emigration rates from 1979 until 2015. Notice that from 2005 these rates are constant, equal to the ones in $2005 \ldots \ldots \ldots$. . . . . . . . . . . . . . . . 4 40 
3.5 Model fitting since March 1st 1979 to March 3rd 1996 and future prediction for each subpopulation, $E, N, V$ and $A$. Points on the left are data of election days, the continuous lines the solution of the model until 2020. The $90 \%$ confidence intervals for electoral years with their mean are on the right. . . . . . . 44

4.1 Graph depicting the model (4.1)-(4.3). Circles are the subpopulations and arrows represent the flow of people who change their attitude towards ETA over time. . . . . . . . . . 51

4.2 Graph representing the fitting. The lines are the corresponding model functions and the points are data from Table 4.1. Support subpopulation $A_{1}(t)$ on the left, Rejection subpopulation $A_{2}(t)$ in the middle, and Abstention subpopulation $A_{3}(t)$ on the right. . . . . . . . . . . . . . . . . 52

4.3 Graph of model prediction after LPP (Jun 2002) until May 2005 (line) with data from Table 4.2 (points). The question is if the differences are due to model-fitting errors (nonsignificant) or are due to the LPP (significant). . . . . . . . 52

4.4 In this graph we show the attitude towards ETA (points), the model deterministic prediction (line) and the error bars corresponding to $90 \%$ confidence intervals in the same time instants as we have data in Tables 4.1 and 4.2. The points inside the confidence intervals are the mean of the 5000 outputs for every subpopulation in every time instant. The vertical axis is placed on the time instant when the LPP was passed (Jun 2002). 56

5.1 Graph depicting the model (5.1)-(5.3). The circles are the subpopulations and the arrows represent the flow of people who change their attitude towards ETA over the time. . . . . 61

5.2 Probabilistic estimation. The vertical segments (error bars) correspond to the $95 \%$ CI of the simulated data using multinomial distributions appearing in Table 5.2. The points in the middle of the segments are the mean values in Table 5.1. The continuous lines are the model 95\% MCB (probabilistic estimation) obtained with the described procedure. Note that most of the segments cross continuous lines determined by the model, capturing the data uncertainty. Only for Rejection and Abstention subpopulations in time instants Nov 2006 and May 2007 the uncertainty is not captured. . . . . . . . . . . 67 
5.3 Probabilistic prediction. This picture is the Figure 5.2 including the predictions over the next four years as $95 \% \mathrm{MCB}$ (model continuous lines). . . . . . . . . . . . . . . . . . . . . 69 


\section{List of Tables}

3.1 Data corresponding to graphic in Figure 3.2. . . . . . . . . 36

3.2 Deterministic prediction for the next electoral years 2012, 2016

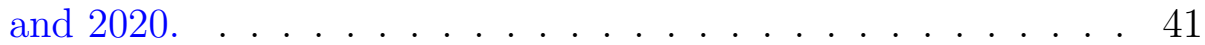

$3.390 \%$ confidence intervals obtained with 5,000 model outputs using LHS technique in the next electoral years 2012, 2016 and 2020 .

4.1 Percentage of people in the Basque Country with respect to their attitude towards ETA from May 1995 to May 2002, when the LPP was passed (pre-LPP scenario). . . . . . . . . . 48

4.2 Percentage of people in the Basque Country with respect to their attitude towards ETA from Nov 2002 to May 2005, after the passing of the LPP until the granting of the permission by the Spanish Parliament to conduct a dialogue with ETA (post-LPP scenario). . . . . . . . . . . . . . . . . . . . . . . . . 49

4.3 Estimated model parameters. . . . . . . . . . . . . . 51

4.4 Residual or error terms. $A_{i}(t)$ are the real data (Table 4.1) and $\hat{A}_{i}(t)$ are the predictions of the model. . . . . . . . . . 53

4.5 Means and $90 \%$ confidence intervals of the model output. We estimate these predictions (point prediction and interval prediction) solving the model (4.1)-(4.3) for each one of the 5000 sets of parameters calculated by fitting the model with the perturbed pre-LPP data. . . . . . . . . . . . 55

4.6 Distances between Table 4.2 data and the extremes of their corresponding $90 \%$ confidence intervals. Intervals with negative values mean that the attitude prevalence datum lies inside the $90 \%$ confidence interval. . . . . . . . . . . . . 56

5.1 Percentage of people in the Basque Country with respect to their attitude towards ETA from May 2005 to Nov 2012. . . . 60 
5.2 Data for probabilistic model estimation. Date, sample size and joint trinomial probability function of each survey. Using these distributions we will be able to compute their $95 \%$ confidence intervals. Also, the model will be fitted with samples of these probability distributions. . . . . . . . . . . . . . 63

5.3 Mean and 95\% confidence interval predictions for the coming eight Euskobarometro surveys. . . . . . . . . . . . . . . . 68

5.4 Mean and 95\% confidence interval predictions for the coming eight Euskobarometro surveys for the second procedure execution, $k=129$ and $m_{k}=0.9624 \ldots \ldots \ldots \ldots$

5.5 Mean and 95\% confidence interval predictions for the coming eight Euskobarometro surveys for the third procedure execution, $k=84$ and $m_{k}=0.966348 \ldots \ldots \ldots \ldots$

5.6 Mean and 95\% confidence interval of the Euskobarometro corresponding to May 2013. . . . . . . . . . . . . . . . 71 


\section{Chapter 1}

\section{Introduction}

Extreme political acts are usually produced by small groups but their actions have impact on a large number of people. Fear is a strategy developed by these groups to influence the decisions of the whole population in order to achieve their political goals. This fact allows us to consider ideologies in general and extreme ideologies in particular, as if they were diseases that spread by peer pressure or social contact between friends, environment, fear, threats, extortion, vandalism, terrorism, propaganda, law enforcement, mass media, etc., and therefore, type-epidemiological models may be useful tools to understand the evolution dynamics of these ideologies. Although it can be considered as a natural assumption and it is supported by works of N.A. Christakis, J.H., Fowler [23], for instance, it does not seem so clear in Political areas of knowledge and this will lead us to propose a specific justification in Section 4.2 of this dissertation.

The understanding of the transmission dynamics of such a type of behavior increases our knowledge of the mechanisms behind the evolution of cultural norms and values. To do this, mathematical modelling is a tool that may help to predict the evolution of the extreme groups over the time, eventually disappearing or establishing themselves.

This area of study has been active since the September 11th attacks, not only in the study of the behavior of extreme groups, but also in how to handle bio-terrorist threaten [8].

The use of the type-epidemiological approach is not new but the few papers that can be found nowadays in the literature are mainly based on the Castillo-Chávez \& Song's work [17] and the antecedent [12] where the authors propose a model of spreading ideas. Some of these works are $[62,63]$ where they present network versions of model introduced in [17] or [2] where the authors deal with the case of the insurgency in Colombia using predator-prey modelling techniques or in [19] where a mathematical model of the dynamics 
of radicalization process on socio-spatial networks is studied. Also, there are some communications in congresses as $[5,57,58]$. Moreover, the introduction of non-linear models of electoral change have also been proposed [64].

Even though some of the above papers are based in [17], in this paper, Castillo-Chávez \& Song say that "... we study the dynamics of the spread of extreme behavior as some type of epidemiology contact processes. We are aware that our approach and the associated caricature model (as most sociological models) can be easily derailed or deconstructed. We hope that our efforts are not taken that lightly, as we believe that epidemiological models still represent a reasonable starting point for the study of the spread and growth of behavior that are the engine behind most acts of terrorism".

The above comment is pertinent not only because the authors know that the model they propose is a limited first approach, but also because mathematical modelling in Social Sciences, in general, and in a complex phenomenon as terrorism or fanaticism in particular, is not an easy task. The reasons of this difficulty may lie in the uncertainty and complexity of the social phenomena as well as in the novelty of using dynamical models based on differential equations in an area where Statistics is practically the only methodological tool for quantification. This explains the effort and, sometimes, incomprehension when mathematicians try to collaborate with professionals in Social Sciences trying to find a common language to understand each other.

We should also say that all the papers referred above propose theoretical models where a dynamic analysis is performed. The dynamical analysis is a powerful tool, nevertheless, as Castillo-Chávez \& Song wrote in [17] "... even though the core population is on its way of extinction, it can still experience grow and expand in finite time before it begins to decay", and this finite time may be long. This fact leads us to use real data to build models to work with, providing an additional value to our work because we will be able to describe the groups behavior not only in the long run, but also in medium and short term, what may be more realistic if the objective is to use the models to simulate new policies related to model parameters and see the effects. Furthermore, working with real data constitutes an additional effort controlling the uncertainty in parameter estimation and also the propagation of the mentioned uncertainty in the model predictions.

In this dissertation, we focus our study in the especial situation occurring in the Basque Country [67], a Northern Spanish region, where the Basque revolutionary organisation ETA (Basque for "Basque Homeland and Freedom") [70] has been using different forms of terrorism to achieve its political goals during the last 50 years. The existence of an extreme left wing terrorist organization [54] in a democracy as is Spain is unique all around the world, 
except, maybe in Colombia, where the jungle and mountains help the FARC to establish, in some hidden areas, its own government [52].

ETA declared a cease-fire in Jan 2011, at this moment it is not attacking and, as we can see in Figure 1.1, there is a reduction in the percentage of Basque people concerned about violence and terrorism.

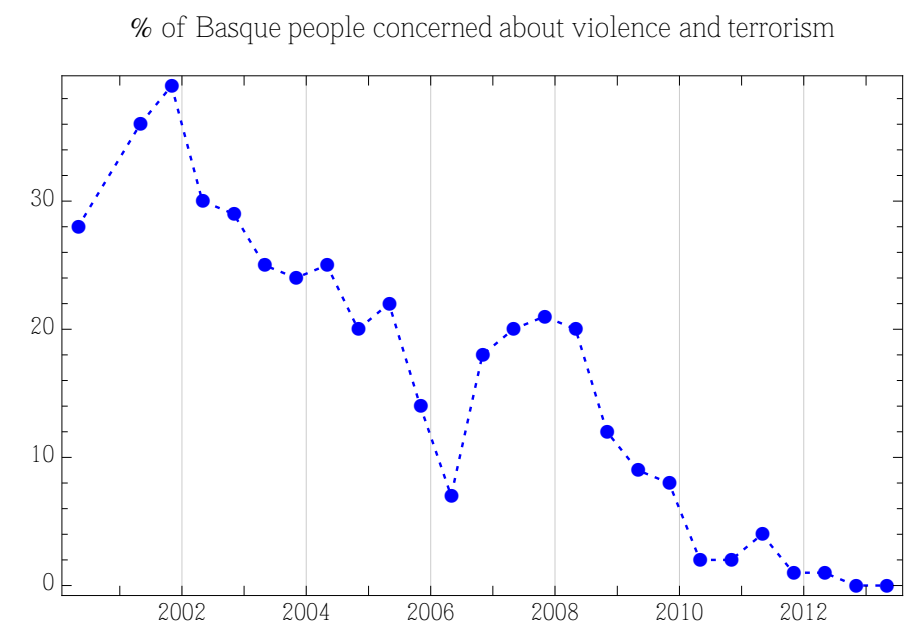

Figure 1.1: Percentage of Basque people concerned about violence and terrorism over the time since May 2000 until May 2013 [33].

Despite this reduction, nowadays, around $50 \%$ of Basque people do not feel free to talk about politics and around $25 \%$ of Basque people have a lot or quite fear to participate actively in politics in the Basque Country (see Figure 1.2). It does not seem a typical scenario of democratic normality. In fact, there are groups related to ETA that pressure the society to achieve their goals. Moreover, we should not forget that ETA still has not abandoned violence definitively and it would not be the first time ETA declares cease-fire that breaks unilaterally and resumes the violent acts. All these facts disclose that the problem of the violence in the Basque Country, and by extension in Spain, is as up-to-date as ever and account for developing the present study.

\section{$1.1 \quad$ Uncertainty}

The treatment of the uncertainty in the models is going to be one of the keys in this dissertation.

Uncertainty quantification in dynamic continuous models is an emerging area [40]. Because of the numerous complex factors that usually involve social behavior, it is particularly appropriate the consideration of random- 
Freedom feeling to talk about politics

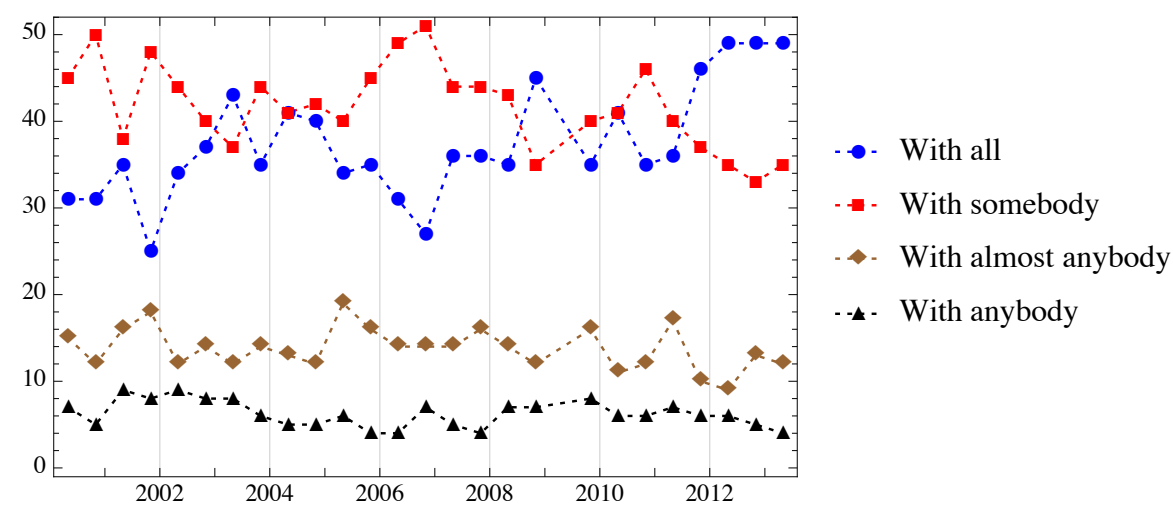

Fear feeling to participate actively in politics

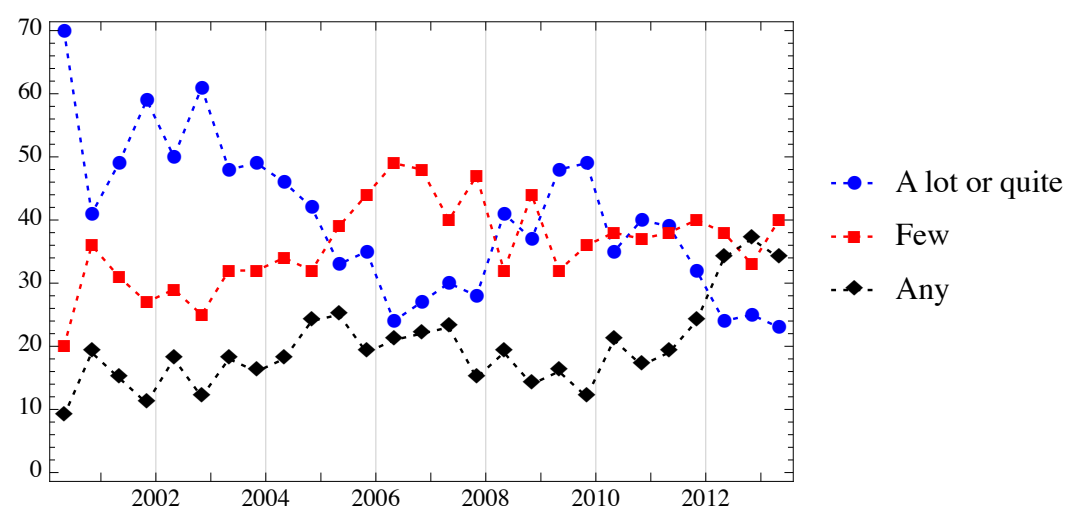

Figure 1.2: (Up) Percentage of Basque people depending on their freedom feeling to talk about politics. (Down) Percentage of Basque people depending on their fear feeling to participate actively in politics. [33].

ness in this kind of models. In practice, the introduction of randomness in continuous models can be done using different approaches. Stochastic differential equations of Itô-type consider uncertainty through a stochastic process called white noise, i.e., the derivative of a Wiener process. As a consequence, this approach limitates the introduction of uncertainty to a gaussian process whose sample trajectories are somewhat irregular since they are nowhere differentiable. A more convenient approach in social modelling is to permit that input parameters can become random variables and/or stochastic processes and, therefore can follow other type of probability distributions apart from gaussian. This approach leads to continuous models usually referred to as random differential equations (r.d.e.'s). In dealing with r.d.e.'s, generalized Polynomial Chaos (gPC) is likely one of the most fruitful methods [36, 65]. 
Most of the existing methods and techniques, start with the assumption that the model parameters follow a known standard probability distribution. In general, setting the probability distribution of the model parameters, standard or empirical, is a crucial and difficult task currently under study which is required for model uncertainty approaches.

Also, the computation is an important issue in dealing with uncertainty. For instance, gPC technique may not be affordable when the number of model parameters with uncertainty increases, or the interval where the mean and the standard deviation are valid may be very short [18]. It may turn these techniques inappropriate for modelling real problems.

On the other hand, if we consider that no information is available for setting the model parameters probabilistic distribution, techniques as bootstapping $[22,53]$ or bayesian [20] are other useful approaches.

\subsection{Overview of the dissertation}

Popular support is an important enabler for radical violent organizations and it may be crucial for their survival. At the same time, extremist groups have also an impact in the societies where they are inserted, especially if those groups are engaged in violent activities. Social and behavioral scientists try to find clues about how that interaction may affect those people, either at the group or at the individual level, in order to foresee subsequent dynamics.

In this dissertation, our objective is to shed light on the dynamics about the attitude the Basque Country population have towards ETA, its goals and the means it uses to achieve them. To do that we use mathematical models and introduce uncertainty into these models step by step, in a natural way as an intrinsic part of modelling in Social Sciences.

In particular, we focus on the events that affect the attitude towards ETA, the effect of the Law of Political Parties (LPP), the influence of the truces, the relation between ETA's supporters and the source of ETA's activists, the prediction of the evolution of ETA's supporters, etc. All the above facts involve uncertainty in the model and through the present dissertation we will explain how we introduce the uncertainty treatment in each one of the presented models, rough first and more sophisticated at the end.

In the following, we present a content description of this $\mathrm{PhD}$ dissertation. Also, we report its historical developing because it explains some decisions we made during the progress of this work.

We start in Chapter 2, where we describe the organization ETA and its main facts in order to justify the interest of studying the ideological evolution of the most affected people, the Basques and the Spanish. Moreover, we 
introduce the Euskobarometro, a sociological statistical survey in the Basque Country that will provide us source data. Also, we will give some interesting references to understand the "Basque problem" (using ETA's language) and the role of ETA.

Our first modeling approach is presented in Chapter 3. Here we classify the population depending on the party they vote, then we grouped the political parties respect to their attitude on the "independence from Spain", one of the ETA's most important goals, using the parties' electoral manifestos. Thus, using electoral data, we are able to divide the population in the Basque Country into people that:

- agree with ETA in the objective of independence and the use of violence to achieve it,

- agree with ETA only in the objective of independence, without the use of violence,

- completely disagree with ETA.

Then we present a type-epidemiological model to study the dynamics of these groups over the time and introduce uncertainty in the prediction over the next few years using a technique called Latin Hypercube Sampling (LHS).

Part of the results presented in this chapter were published [59]. However, we should say that other paper related to Chapter 3 was prepared introducing the uncertainty using LHS not only in prediction but also in model simulations of the effect of some policies over the next few years. It was sent to journal Terrorism and Political Violence and a negative answer was received. In fact, the referees pointed out some important drawbacks as

1. "Terrorism and the ideology behind terrorism are subjects that are defined by a myriad of complex ideological, social, economic and political factors",

2. "In fact, the methodology is extremely confusing, not only because of its quantitative nature, but also as a result of the questionable model employed which presents ideology as a socially transmitted epidemic disease",

3. "The author builds up his/her model on a set of sources which also reveal a limited grasp of the most relevant literature on the subject. The author completely ignores the work of key writers on the Basque conflict", 
4. "There is not a single mention to other primary sources that are much more relevant than the ones used by the author. For example, the periodical sociological and political surveys produced by the Euskobarometro or the regular reports on the violent activity of ETA produced by the Interior Ministry are key sources for anybody who wants to analyze precisely what the author wants to analyze",

5. "The author completely ignores the variety of identities within Basque society and the social support for each of these ideological stances. Instead the author wrongly simplifies such a complexity of political identities by summarizing them in the following categories: E, nonnationalist people against independence and the use of the violence; $\mathrm{N}$, nationalist people agree with independence but disagree with the use of the violence; $\mathrm{V}$, nationalist people agree with independence and the use of the violence, and A, people who do not share the above mentioned ideological characteristics or people who abstain. As regular surveys have shown for many decades, the majority of the nationalist population of the Basque Country do not advocate independence",

6. "The data on the different ideological stances among Basque population has been extracted from incomplete sources leaving out other sources which are much more up to date and relevant",

7. "In a nutshell, the article presents a very simplistic, sketchy picture of a complex, multifaceted issue and fails to provide a clear contribution to the understanding of the subject",

and so on. Nowadays, we admit most of them, except the 2nd (of course), but the most important for us was to figure out how far was our language, method, argumentation and mind from those experts in political sciences, terrorism and extreme ideologies.

Therefore, we needed an expert partner and we were so lucky that he found us before we started searching. The expert addressed us to study a relevant problem in the area, what was a change in our way, and the results are presented in Chapter 4.

About the use of LHS technique to deal with the model uncertainty, we should say that it is satisfactory as a first attempt, however we had to assume the fact that the model parameters follow a uniform distribution (because we do not have information about them) with an unknown variation we had to establish in $20 \%$.

Following the suggestions of the expert, in Chapter 4 we study whether the "Law of Political Parties" (LPP) had an effect on attitude of the Basque 
population towards ETA and we tried to quantify this effect. In June 2002, the Spanish Government passed the LPP with the aim, among others, to prevent parties giving political support to terrorist organizations. This law affected the Basque nationalist party "Batasuna", due to its proved relation with ETA. Then, taking data from the Euskobarometro (Basque Country survey) related to the attitude of the Basque population towards ETA, we propose a dynamic model for the pre-LPP scenario. This model will be extrapolated into the future in order to predict what would have happened to the attitude of the Basque population if the law had not been passed. These model predictions will be compared to post-LPP data from the Euskobarometro using a bootstrapping approach in order to quantify the effect of the LPP on the attitude of Basque Country population towards ETA.

In this chapter, the uncertainty is studied applying a bootstrapping technique to the dynamic model. Bootstrapping technique was a satisfactory technique (we give an answer to the problem), but during its application we realised that, to be applied, it has to fulfill restrictive hypotheses and it does not consider the uncertainty in the initial condition.

In the current times, where there are important political parties, mass media and organizations supporting the negotiation with ETA as the best choice to finish its activities, the Chapter 4 supports that the opposite idea may be possible, this is, the appropriate use of the laws is an useful tool to fight against these extreme organizations and change the citizen's mind against the social pressure. Moreover, even though it is not reflected in the chapter but can be seen in Figures 2.1, 2.2 and 2.3, although relevant changes and events have occurred, the support attitude towards ETA of the Basque population has hardly varied (moving around 4\%) since LPP. That is, despite of what uses to happen with other laws which effect disappears in two or three years returning to pre-law figures with independence of the time they are into force [37], the Law of Political Parties seems to have produced a permanent effect on the attitude of the Basque population towards ETA. The results presented in Chapter 4 have been published in [53].

We also should say that this is one of the few works that, using dynamic models, tries to quantify the effect of a law. The only reference we know using a similar technique is [37] where the effect of Spanish tobacco law in 2006 is analysed.

The objective in Chapter 5 is to analyse the evolution dynamics of the populations in Chapter 4 using the same model from May 2005 to Nov 2012 in order to predict the future evolution of the attitude of the Basque population towards ETA, taking into account that Supporters may be considered as the main source of ETA members. To get this objective, we propose and apply a new computational technique to deal with uncertainty in dynamic continuous 
models without the drawbacks of LHS and bootstrapping. Considering data from surveys, the method consists of determining the probability distribution of the survey output and this allows to sample data and fit the model to the sampled data using a goodness-of-fit criterion based on the $\chi^{2}$-test. Taking the fitted parameters non-rejected by the $\chi^{2}$-test, substituting them into the model and computing their outputs, we build $95 \%$ confidence intervals in each time instant capturing uncertainty of the survey data (probabilistic estimation). Using the same set of obtained model parameters, we also provide a prediction over the next few years with $95 \%$ confidence intervals (probabilistic prediction).

Finally, in Chapter 6 we enumerate the main goals this dissertation achieved. 


\section{Chapter 2}

\section{Euskadi Ta Askatasuna (ETA)}

ETA defines itself as "(...) a Basque socialist revolutionary organization for national liberation" $[21,32,70]$. One of its core demands is the creation of a Basque State, which would encompass the current three Basque Provinces and Navarra, in Spain, and three more French provinces. According to the Spanish Ministry of Internal Affairs, ETA has committed 829 murderers since 1968 [48], although this figure is under debate [29].

After 50 years of activity, ETA has been proscribed as terrorist organization by the Spanish authorities, the European Union [54], the USA and the United Nations. The long duration of ETA has been studied in [10].

Batasuna was a left-wing nationalist party and, as the Spanish Supreme Court stated, it was the ETA's political wing [60].

In June 2002, the "Law of Political Parties" (LPP) was passed in the Spanish Parliament and its goals were "(...) to guarantee the democratic system and citizen's essential freedoms, by preventing some political parties from threatening democracy, justify racism and xenophobia or give political support to terrorist organizations" [41]. As a consequence of this law, in August 2002, the suspension of the activities of the party Batasuna and the closing of its headquarters was decreed. However, the fact is that Batasuna persisted in political activities banned by the LPP. That circumstance led the Supreme Court to outlaw that organization in March 2003, which implied the eventual cessation of all its activities and the confiscation of its possessions [60]. The organization to conduct any political meeting or propaganda activities was also specifically prohibited [6]. In June 2003, Batasuna and other related parties were included, as a part of ETA, in the list of terrorist organizations in the European Union [54].

The LPP meant a substantial change in the anti-terrorist policy in Spain. In practical terms, once Batasuna was outlawed, this party could not present candidates to elections and consequently, ETA and its environment were 
not going to be supported from political institutions nor funded by public budgets.

In May 2005 the Spanish Parliament gave to the Government the possibility of supporting dialogue processes with ETA given that appropriate conditions to end violence occur [15, Resolución 34, p. 13], what was a change in the anti-terrorist policy because the last time the Spanish Government tried to negotiate with ETA was when the Popular Party (conservative-center wing) won elections in March 1996. Even though the LPP is still into force, the opened dialogue process led, in our opinion, to two main political facts: new left-wing nationalist parties were allowed again to present candidates in elections, and ETA began its "permanent and verifiable cease-of-fire", in Jan 2011 [32].

In regard to the elections, in local elections in May 2007, the left-wing nationalist party $E A E-A N V$ was allowed to present candidates in some villages and cities. In local elections in May 2011, without restrictions, the coalition BILDU-EA-ALTERNATIBA obtained around $25 \%$ of votes and was the second most voted party in the Basque Country [66]. In Spanish Parliament elections in Nov 2011, under the name AMAIUR, was also the second most voted party in the Basque Country with $24.11 \%$ of votes obtaining 6 seats [66]. Finally, in the Basque Country Parliament regional election, under the name of $E H-B I L D U$, they obtained $25 \%$ of votes and 21 seats [69].

\subsection{Euskobarometro and the attitude of the Basque population towards ETA}

In order to perform a complete and thorough study, we need to know data about the sociological situation in the Basque Country respect to ETA and to do that, one of the most recognised sources is the Euskobarometro. Euskobarometro [33] ("Basque-barometer") is a sociological statistical survey in the Basque Country. It is conducted by the Department of Political Science of the University of the Basque Country and it is based on personal interviews at home, asking questions about the sociological current issues, including ETA.

As we mentioned in the Introduction, popular support is an important enabler for radical violent organizations and it may be crucial for their survival. At the same time, extremist groups have also an impact in the societies where they are inserted, especially if those groups are engaged in violent activities. Social and behavioral scientists try to find clues about how that interaction may affect those people, either at the group or at the individual 
level.

Thus, taking data series from Euskobarometro survey, in Figures 2.1, 2.2 and 2.3 we can see the evolution of Basque Country population with respect to their attitudes towards ETA since May 1995 until Nov 2012 (question 20 of the Euskobarometro).

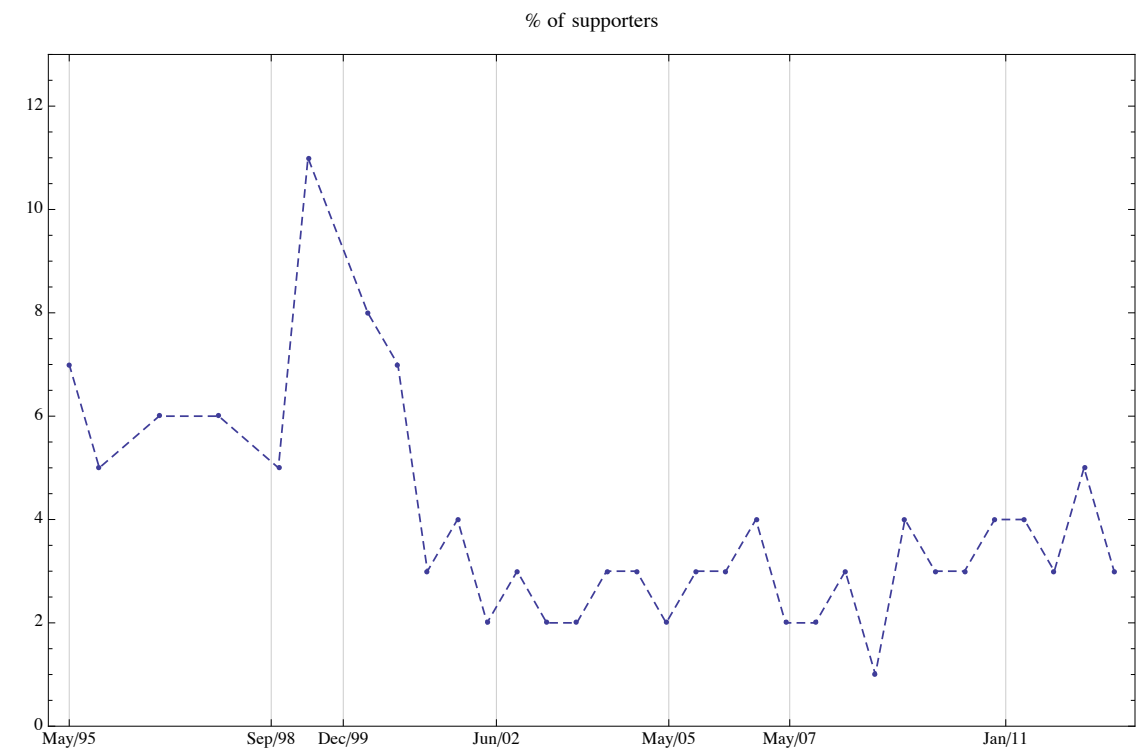

Figure 2.1: Percentage of Basque Country population with an attitude of support towards ETA since May 1995 until Nov 2012. Vertical lines correspond to remarkable dates.

The vertical lines in Figures 2.1, 2.2 and 2.3 correspond to remarkable dates: in Sep 1998, ETA announced an unlimited cease-fire without conditions; in Dec 1999, ETA announced the end of the cease-fire and the resume of violence; in Jun 2002 the LPP was passed; in May 2005 the Spanish Parliament gave to the Government the possibility of supporting dialogue with ETA; in May 2007 the left-wing nationalist party could present candidates again; in Jan 2011 ETA announced a permanent cease-fire.

Observe that large jumps in the Rejection population correspond to large jumps in the Indifferent/Abstention population, in the opposite direction. Furthermore, note that, since Jun 2002 when the LPP passed, the percentage of Basque people having a supporting attitude towards ETA is around $4 \%$.

It is remarkable that events with high repercussion in social media hardly produced changes on the attitude of Basque Country population towards ETA. As examples, we mention the kidnapping during 532 days (Jan 1996 - Jul 1997) of José Antonio Ortega Lara [78, 79], or the kidnapping and 


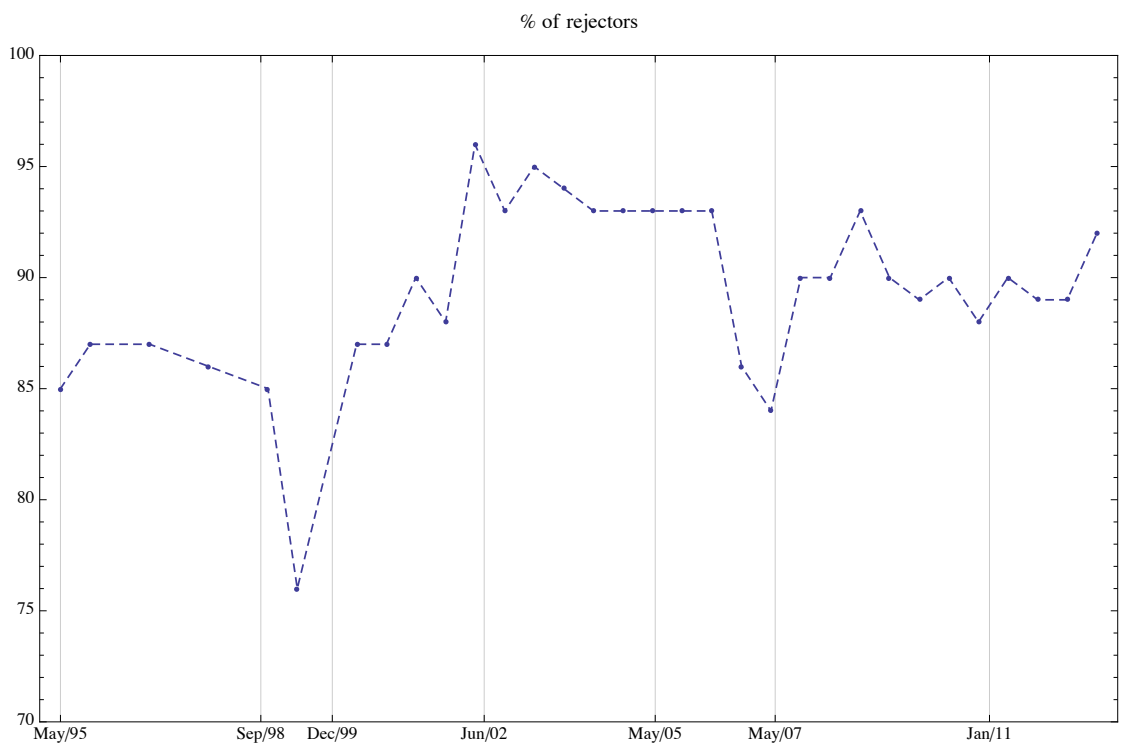

Figure 2.2: Percentage of Basque Country population with an attitude of rejection towards ETA since May 1995 until Nov 2012. Vertical lines correspond to remarkable dates.

murdering of Miguel Ángel Blanco [75, 76, 77] Jul 10th-12th, 1997, or, even though not related to ETA, the March 11th, 2004 Madrid train bombings $[25,80]$.

\subsection{Current situation}

As a consequence of the LPP, at this moment, there is a singular situation where:

- It seems that ETA has become weaker [39, 71, 72, 73].

- Most of the Basque society (87\%) considers ETA a lot or quite negative [34, p. 57].

- Basque left-wing nationalist parties are the second most voted [66, 69]. We mentioned above when we described the left-wing nationalist electoral results (page 26).

- Relevant people in the Basque Country, for the first time, dare to say that ETA may be an obstacle to get the objectives of Basque nationalism [74]. 


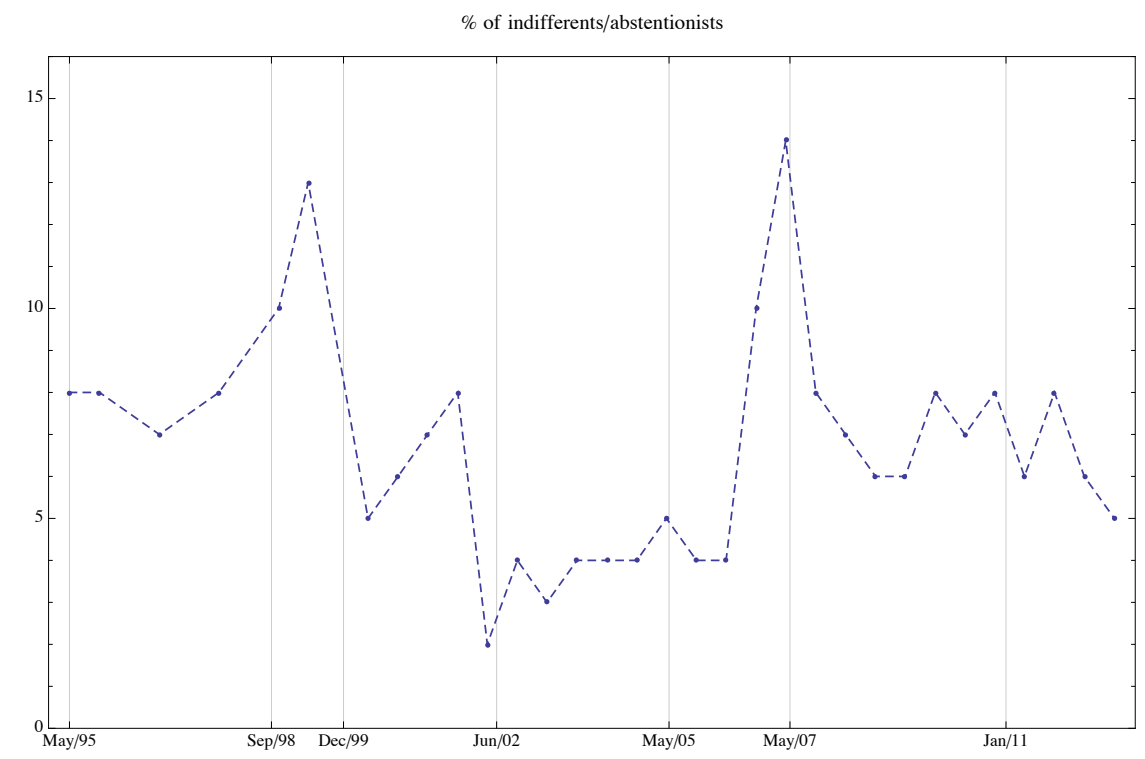

Figure 2.3: Percentage of Basque Country population with an attitude of indifference/abstention towards ETA since May 1995 until Nov 2012. Vertical lines correspond to remarkable dates.

Despite the growing of the left-wing nationalism, the supporting attitude towards ETA does not grow, therefore, not all the Basque people who vote nationalist or pro-independence options agree with ETA. In fact, in [34, p. 57] the authors of the Euskobarometro report say that ETA's permanent cease-fire has been the key of the electoral recovery of the left-wing nationalist parties and currently, the supporters of ETA are only around $14 \%$ of the people who vote left-wing nationalist parties [34, p. 56-57]. The remainder $86 \%$ does not have a support attitude towards ETA. However, these supporters and their environment, hypothetical pool of candidates willing to join the organization in upcoming years, have had a certain stability in the last decade. Therefore, it would be interesting to study and predict the dynamic evolution of the three populations (Supporters, Rejectors and Abstentionists) over the next few years in order to know if the current scenario (anti-terrorist policies, population expectations, political situation, etc.) could foster ETA eventually dying out by reducing the Supporters population.

In order to address this challenge, we should realise that there was a network of organizations related to ETA and its social wings as religious groups, training programmes, mass media (Egin), ecologist groups (Eguzki), women organizations (Egizan), anti-drug programmes (Azkagintza), students (IA and OMEV) and children (Kimuak and Champiñón) groups, Basque 
language programmes (AEK and Euskalherrian Euzkaraz), international solidarity (Askapena) and prisoners and refugees [42]. Also, these organizations had buildings and pubs where meet and develop their activities [51, 60], providing a closed way of life to their members based on its political ideology. Thus, ETA and its environment can keep constant pressure on the Spanish government and the remainder Basque (mainly the non-nationalist) population. Some of them, finally, cannot take the pressure and have to migrate $[3,26,44]$. These points give strength to approach the problem using epidemiology techniques.

ETA appears in several publications, in the economic study of the impact of terrorism $[1,16,30,31]$, in statistical techniques applied to understand its terrorist activities $[9,10,11]$ or in interrelated issues of terrorism, human rights and law enforcement in a context of political change [4]. In [51] the author presents a functional approach to radical violent groups, focusing in ETA and its environment, and proposing a model describing the process by which young people are recruited by these groups. More details and history of ETA can be found, for instance, in $[10,11,28,56]$. 


\section{Chapter 3}

\section{A first mathematical model of the evolution of the Basque Country population respect to their opinion about ETA under its pressure}

In this chapter, our objective is to state a first type-epidemiological mathematical model. This model study the evolution over the time of populations in the Basque Country respect their opinions about the ETA's goals. This way, as we mentioned in Section 2.2, we want to focus on the evolution of the supporters of ETA's goals to see if they decrease or not.

Here, we recall that popular support is an important enabler for radical violent organizations and it may be crucial for their survival and these extremist groups have also an impact in the societies where they are inserted, especially if those groups are engaged in violent activities.

The democratic system in the Basque Country and in the rest of Spain is affected by terrorist acts of ETA (murders, kidnapping, vandalism, etc.). Thus, terrorism uses to be one of the most important topics for Spanish public opinion.

In order to carry out this study, the Basque Country' population will be divided into people that:

- agree with ETA in the objective of independence and the use of violence to get it,

- agree with ETA only in the objective of independence, without the use of violence, 
- completely disagree with ETA.

Then, from electoral manifestos and using statistical techniques, in Section 3.1, a classification of different political parties respect to the political goal "independence" is done. This allows us to divide the Basque population depending on their support to ETA's goals. In Section 3.2 a typeepidemiological mathematical model where the pressure of ETA and its related groups affects the opinion of the people about the support of ETA's goals, is proposed. The model developed in Section 3.2 is not appropriate for data obtained in Section 3.1 (same units), hence Section 3.3 is devoted to scale the model properly to be fitted with classification data obtained in Section 3.4. Simulations to predict short- and medium-term evolution of population in the Basque Country deterministically and with uncertainty are presented in Section 3.5. Finally, Section 3.6 is devoted to conclusions.

\subsection{Classification of ideological groups}

Let us consider as source data the results of the general elections to the Spanish Parliament in the Basque Country since June 15th 1977 to March 14th 2004 [66]. Since 1977, 85 political parties nominated candidates to, at least, one general election in the Basque Country electoral district. General elections data have been considered because, in Spain, experts consider that general elections give a more realistic political distribution than local elections [13].

Now, let us classify the parties with respect to their relation with the political objective "independence". To do this, a survey is prepared to be answered from the party's election manifestos. The survey consist of the following questions (or ideological characteristics):

1. Nationalist (Yes/No),

2. Religious (Yes/No),

3. Supports violence (Yes/No),

4. Interventionist (Yes/No),

5. Ecologist (Yes/No),

6. Independence (Yes/No),

7. Ideology (right wing or center/left wing/nationalist). 
A non-parametric bivariant analysis [24, Chap. 9] is carried out in order to determine the ideological characteristics (questions of the survey) related to the use of the violence to get the independence. These characteristics were "Independence", "Nationalism", "Ideology" and "Support violence" with associated $p$-values less than 0.01. In the multiple correspondence analysis [38, Chap. 10] three different profiles can be seen (see Figure 3.1), nationalist parties agreeing with the independence and the use of violence, right-wing and center parties against independence and, in the middle of these profiles, left-wing parties with a non homogeneous and/or ambiguous position respect to independence and the use of violence.

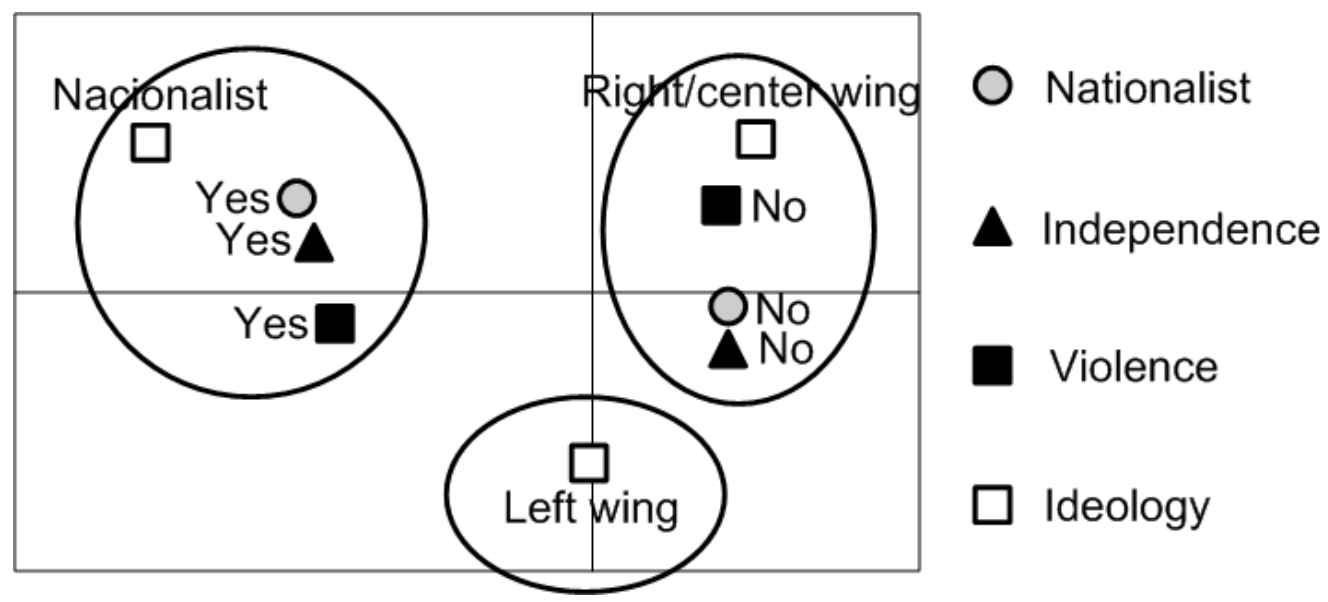

Figure 3.1: Correspondence analysis shows three different profiles, nationalist parties, right-wing and center parties, and left-wing parties with ambiguous positions respect to independence and the use of violence.

These three profiles (defined by the characteristics "Nationalist", "Independence" "Ideology" and "Support violence") lead us to do a non hierarchical cluster analysis with three groups of parties, whose definition is determined by the following characteristics:

- Group $G_{1}$ : non-nationalist parties against independence and the use of the violence.

- Group $G_{2}$ : nationalist parties agreeing with independence but disagreeing with the use of the violence.

- Group $G_{3}$ : nationalist parties agreeing with independence and the use of the violence. 
The above division of political parties allows us to classify the population depending on the parties they vote and the position of these parties respect to ETA's goals. With this approach, the population of the Basque Country can be divided into four subpopulations

- $E(t)$, number of people who share the common ideological characteristics of parties in $G_{1}$ at time $t$,

- $N(t)$, number of people who share the common ideological characteristics of parties in $G_{2}$ at time $t$,

- $V(t)$, number of people who share the common ideological characteristics of parties in $G_{3}$ at time $t$, and

- $A(t)$, the rest of the people at time $t$. It includes people who do not share the ideological characteristics of groups $G_{1}, G_{2}$ and $G_{3}$ or people who abstain.

Figure 3.2 shows the percentage of votes of each subpopulation in each election.

Two considerations should be mentioned here to understand some trend changes in Figure 3.2 at the beginning and at the end. The general elections in 1977 were the first celebrated after the dictator Franco died. Lots of parties presented candidates, the political situation was not clear and it is reflected in the data. In 2000, political parties in group $G_{3}$ asked abstention and in 2004, the "Law of Political Parties" (LPP) forbade these parties from nominating candidates. In fact, LPP outlawed the political parties that did not condemn the violence. Notice that in 2000 and 2004 abstention increased, but this was because the votes for parties of group $G_{3}$ were considered void, increasing the subpopulation $A(t)$.

All the above leads us to consider only election data since 1979 to 1996 where the major part of time the Socialist Party (PSOE) governed Spain and the same policy against terrorism can be assumed in order to fit the model we will develop in Section 3.2.

Taking into account that, in Spain, only people older than 18 can vote and supposing that children and teenagers have the same way of thinking as their parents, let us assume that data in Table 3.1 gives a general voting distribution of the whole population in the Basque Country, and taking into account the classification of parties, the distribution of the people depending on their support to ETA's goals. 


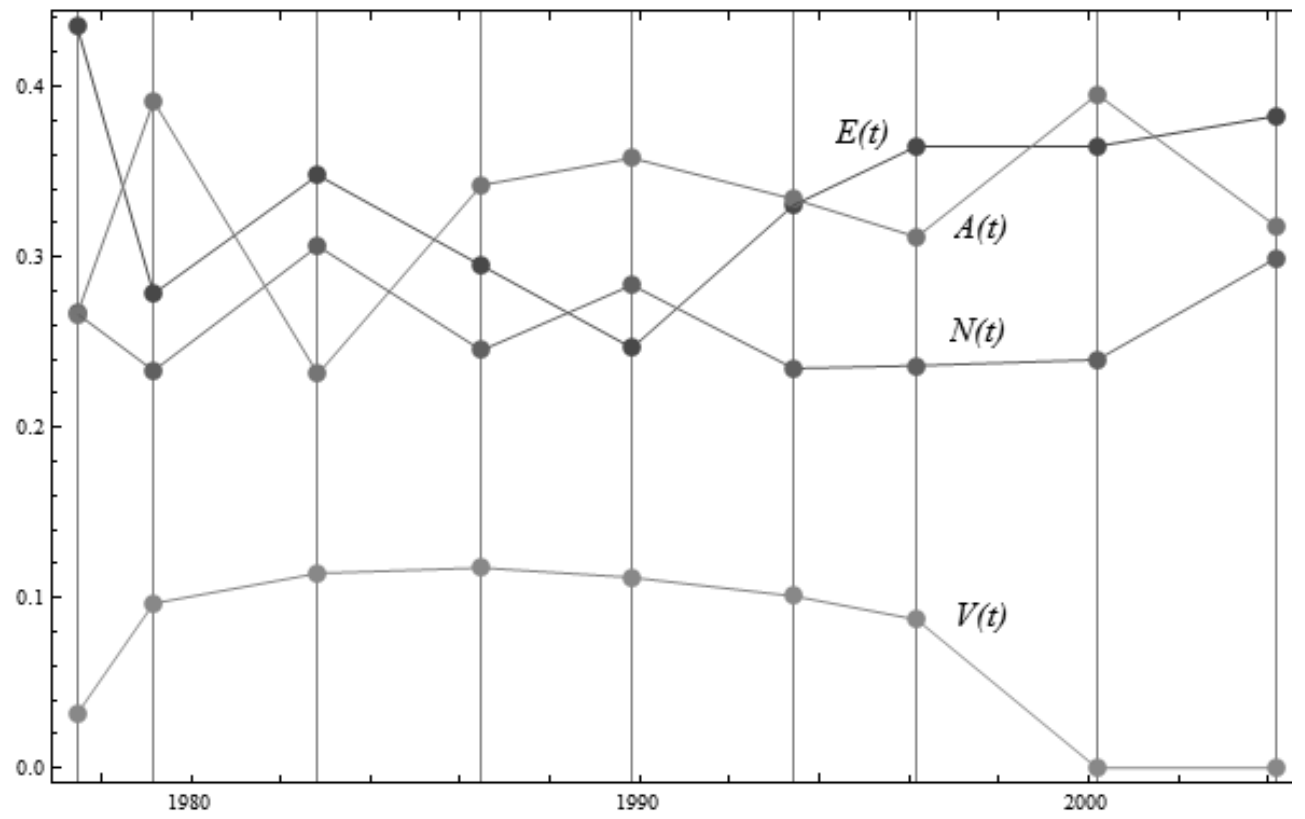

Figure 3.2: This figure shows the percentage of votes of each subpopulation in each election. Vertical lines correspond to electoral days. Let us consider in our study data between 1979 and 1996, where most of the time the Socialist Party (PSOE) was in the government, and the same policy against terrorism can be assumed.

\subsection{Building the type-epidemiological math- ematical model}

Let us consider the population of the Basque Country divided into four subpopulations determined in Section 3.1, that is, $E, N, V$ and $A$. Also, we assume that:

- The number of births $\Lambda(t)$ and the number of deaths $\Phi(t)$ in the year $t$, are proportional to the number of individuals in each subpopulation.

- Terrorism does not increase substantially the number of deaths.

- The immigration $\Gamma(t)$ and emigration $\Sigma(t)$ in Basque Country are also included. It is considered that immigration and emigration only occurs in subpopulations $E$ and $A$ due to the terror pressure $[3,26,44]$ in proportions $\alpha_{1}$ and $\alpha_{2}$, respectively, to be determined. 


\begin{tabular}{lccll}
\hline Election date & $E(t)$ & $N(t)$ & \multicolumn{1}{c}{$V(t)$} & \multicolumn{1}{c}{$A(t)$} \\
\hline Jun 15th, 1977 & 0.435392 & 0.266825 & 0.0316636 & 0.26612 \\
Mar 1st, 1979 & 0.278466 & 0.233303 & 0.0967287 & 0.391502 \\
Oct 28th, 1982 & 0.347978 & 0.306366 & 0.114331 & 0.231325 \\
Jun 22nd, 1986 & 0.294959 & 0.245271 & 0.117587 & 0.342183 \\
Dec 17th, 1989 & 0.246631 & 0.283516 & 0.111871 & 0.357982 \\
Jun 6th, 1993 & 0.330461 & 0.234575 & 0.100969 & 0.333994 \\
Mar 3rd, 1996 & 0.364871 & 0.236203 & 0.0872077 & 0.311718 \\
Mar 12th, 2000 & 0.364974 & 0.239676 & 0. & 0.39535 \\
Mar 14th, 2004 & 0.382756 & 0.299592 & 0. & 0.317652 \\
\hline
\end{tabular}

Table 3.1: Data corresponding to graphic in Figure 3.2.

In order to determine the rest of transition terms, partial correlation coefficients have been used. This coefficient studies the linear relation between two variables under the influence of a third variable [24]. To carry out this study, let us take data of Table 3.1 corresponding to elections from March 1st 1979 to March 3rd 1996.

The partial correlation coefficient between subpopulations $E$ and $A$ under the influence of $V$ is -0.8409 with a $p$-value of $0.009(p-$ value $<0.05)$. It means that there is a linear inverse relation between $E$ and $A$ under $V$, that is, under $V$ an increasing of subpopulation $E$ implies a decrease of subpopulation $A$ and vice versa. Moreover, the linear correlation coefficient between $E$ and $A$ without the presence of $V$ is not significant. Therefore the transition between $E$ and $A$ is not linear because it is only possible under the influence of population $V$, and it is modeled by the nonlinear term

$$
\beta_{1} E(t) \frac{V(t)}{T(t)},
$$

where $\beta_{1}>0$ indicates that the transition is due to the pressure of violent acts and $\beta_{1}<0$ indicates a law enforcement.

Analogously, a similar situation occurs between subpopulations $A$ and $V$ under the pressure of $V$. Then, the transition between subpopulations $A$ and $V$ is modeled by the nonlinear term

$$
k \beta_{1} A(t) \frac{V(t)}{T(t)},
$$

with $k>0$.

On the other hand, the partial correlation coefficient between subpopulations $N$ and $A$ under the influence of $E$ is -0.6292 with a $p$-value of 0.05 
and there is a linear inverse relation between $N$ and $A$ under $E$. Also, the linear correlation coefficient between $N$ and $A$ without the presence of $E$ is not significant. Therefore the transition between $N$ and $A$ is modeled by the nonlinear term

$$
\beta_{2} N(t) \frac{E(t)}{T(t)} .
$$

Then, the system of differential equations that models the evolution over the time of populations in the Basque Country respect their opinions about the ETA's goals under the pressure of its violence is given by

$$
\begin{aligned}
E^{\prime}(t)= & \Lambda(t) E(t)+\alpha_{2} \Gamma(t)-\beta_{1} E(t) \frac{V(t)}{T(t)}- \\
& \Phi(t) E(t)-\alpha_{1} \Sigma(t) \\
N^{\prime}(t)= & \Lambda(t) N(t)-\beta_{2} N(t) \frac{E(t)}{T(t)}-\Phi(t) N(t) \\
V^{\prime}(t)= & \Lambda(t) V(t)+k \beta_{1} A(t) \frac{V(t)}{T(t)}-\Phi(t) V(t) \\
A^{\prime}(t)= & \Lambda(t) A(t)+\left(1-\alpha_{2}\right) \Gamma(t)+\beta_{1} E(t) \frac{V(t)}{T(t)}+ \\
& \beta_{2} N(t) \frac{E(t)}{T(t)}-k \beta_{1} A(t) \frac{V(t)}{T(t)}-\Phi(t) A(t)-\left(1-\alpha_{1}\right) \Sigma(t), \\
T(t)= & E(t)+N(t)+V(t)+A(t) .
\end{aligned}
$$

The above system of differential equations can be represented by the diagram of Figure 3.3.

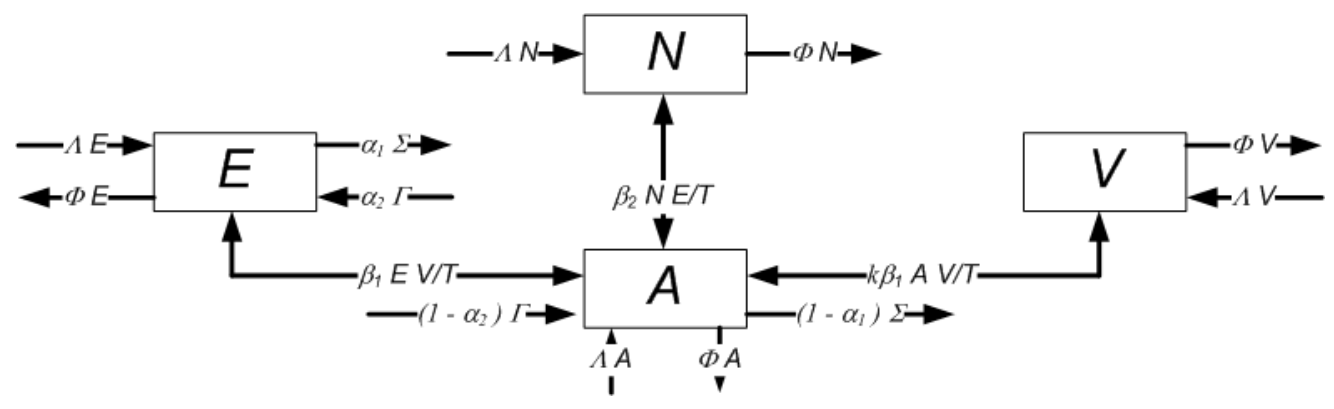

Figure 3.3: Diagram corresponding to the model defined by the system of differential equations $(3.1)-(3.5)$. 


\subsection{Scaling the model $(3.1)-(3.5)$}

Data obtained in Section 3.1 is related to the percentages of population while model (3.1) - (3.5) is related to the number of individuals. It leads us to transform (by scaling) the model into the same units as data, because one of our objectives is to fit the data with the model in next section.

Hence, following ideas developed in $[43,47,81]$ about how to scale models where the population is varying in size, adding equations $(3.1)-(3.4)$ it is obtained

$$
T^{\prime}(t)=[\Lambda(t)-\Phi(t)] T(t)+\Gamma(t)-\Sigma(t) .
$$

Dividing both members of (3.6) by $T(t)$ we have that

$$
\frac{T^{\prime}(t)}{T(t)}=\Lambda(t)-\Phi(t)+\frac{\Gamma(t)-\Sigma(t)}{T(t)} .
$$

On the one hand, if we define the rates (depending on time)

$$
e=\frac{E}{T}, n=\frac{N}{T}, v=\frac{V}{T}, a=\frac{A}{T}, \gamma=\frac{\Gamma}{T}, \sigma=\frac{\Sigma}{T},
$$

equation (3.7) can be transformed into

$$
\frac{T^{\prime}}{T}=\Lambda-\Phi+\gamma-\sigma .
$$

On the other hand, let us compute the derivative of $e$, defined in (3.8). Using (3.9) we obtain that,

$$
e^{\prime}=\frac{E^{\prime} T-E T^{\prime}}{T^{2}}=\frac{E^{\prime}}{T}-\frac{E}{T} \frac{T^{\prime}}{T}=\frac{E^{\prime}}{T}-e[\Lambda-\Phi+\gamma-\sigma] .
$$

In an analogous way, we also have that,

$$
\begin{aligned}
n^{\prime} & =\frac{N^{\prime}}{T}-n[\Lambda-\Phi+\gamma-\sigma] \\
v^{\prime} & =\frac{V^{\prime}}{T}-v[\Lambda-\Phi+\gamma-\sigma] \\
a^{\prime} & =\frac{A^{\prime}}{T}-a[\Lambda-\Phi+\gamma-\sigma]
\end{aligned}
$$

Now, consider equation (3.1). If we divide it by $T$, we have

$$
\frac{E^{\prime}}{T}=\Lambda \frac{E}{T}+\alpha_{2} \frac{\Gamma}{T}-\beta_{1} \frac{E}{T} \frac{V}{T}-\Phi \frac{E}{T}-\alpha_{1} \frac{\Sigma}{T},
$$


using (3.10) and substituting by the corresponding rates defined in (3.8) one gets

$$
e^{\prime}+e[\Lambda-\Phi+\gamma-\sigma]=\Lambda e+\alpha_{2} \gamma-\beta_{1} e v-\Phi e-\alpha_{1} \sigma,
$$

obtaining the scaled equation

$$
e^{\prime}=(\sigma-\gamma) e+\alpha_{2} \gamma-\beta_{1} e v-\alpha_{1} \sigma
$$

The remaining equations can be scaled in the same way to obtain

$$
\begin{aligned}
n^{\prime}= & (\sigma-\gamma) n-\beta_{2} n e, \\
v^{\prime}= & (\sigma-\gamma) v+k \beta_{1} a v, \\
a^{\prime}= & (\sigma-\gamma) a+\left(1-\alpha_{2}\right) \gamma+\beta_{1} e v+ \\
& \beta_{2} n e-k \beta_{1} a v-\left(1-\alpha_{1}\right) \sigma .
\end{aligned}
$$

Notice that the scaled system of differential equations (3.11) - (3.14) is also a non-autonomous system because the immigration $(\gamma)$ and emigration $(\sigma)$ rates depend on time.

\subsection{Model fitting}

Taking data in Table 3.1 corresponding to elections from March 1st 1979 to March 3rd 1996, let us to fit data with the scaled model (3.11) - (3.14) .

Moreover demographic data from [68], in particular annual population, immigration and emigration data in the interval 1979 to 1996 are considered. Hence, in order to compute immigration and emigration rate functions $\gamma(t)$ and $\sigma(t)$, we divide each immigration and emigration datum by the corresponding population datum. Then, we use piecewise linear interpolation to construct both functions, $\gamma$ and $\sigma$. Migration data are depicted in Figure 3.4 .

As initial condition of the model (3.11) - (3.14), it is considered

$$
\begin{gathered}
E\left(t_{0}\right)=0.278466, \quad N\left(t_{0}\right)=0.233303, \\
V\left(t_{0}\right)=0.0967287, \quad A\left(t_{0}\right)=0.391502,
\end{gathered}
$$

where $t_{0}$ corresponds to March 1st 1979 (see Table 3.1). In order to compute the best fitting, we carried out computations with Mathematica [45] and we implemented the function

$$
\begin{aligned}
& \mathbb{F}: \quad \mathbb{R}^{5} \quad \longrightarrow \quad \mathbb{R} \\
& \left(\beta_{1}, \beta_{2}, k, \alpha_{1}, \alpha_{2}\right) \longrightarrow \mathbb{F}\left(\beta_{1}, \beta_{2}, k, \alpha_{1}, \alpha_{2}\right)
\end{aligned}
$$




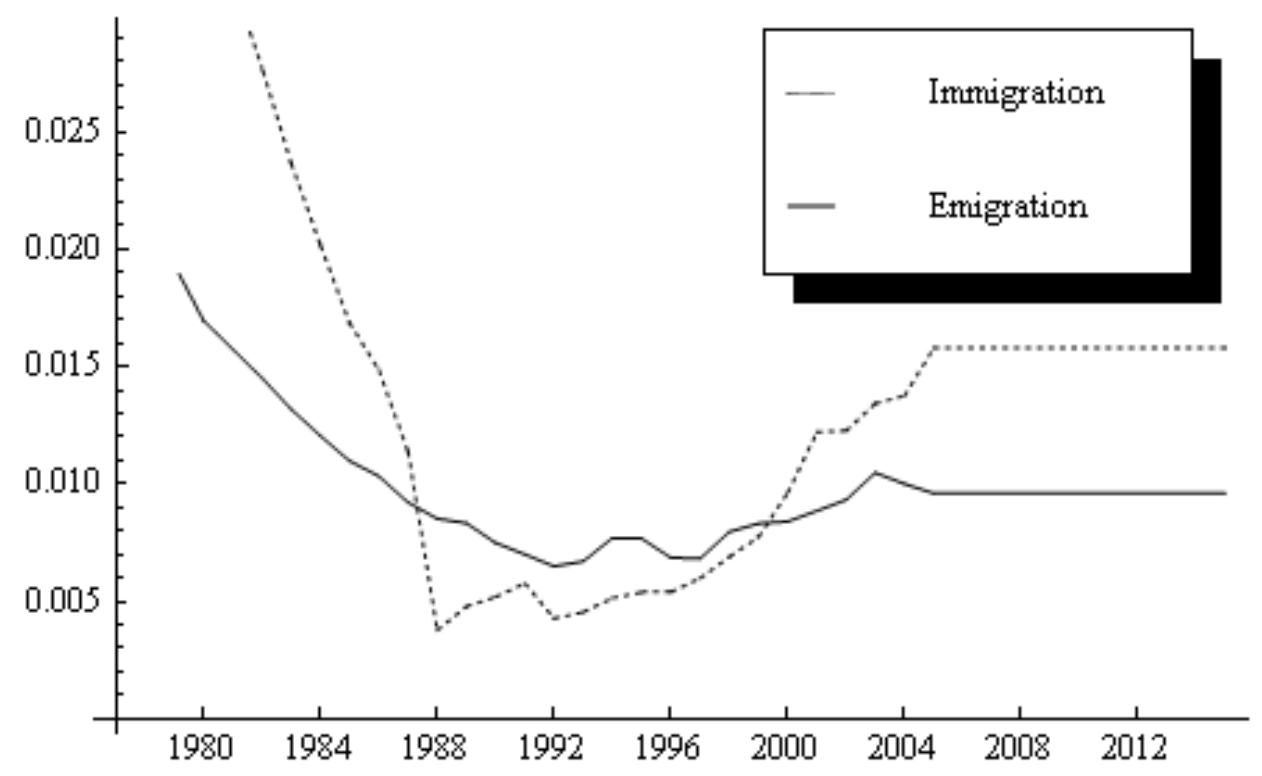

Figure 3.4: Immigration and emigration rates from 1979 until 2015. Notice that from 2005 these rates are constant, equal to the ones in 2005.

which variables are $\beta_{1}, \beta_{2}, k, \alpha_{1}$ and $\alpha_{2}$ such that:

1. Solve numerically (using Mathematica command NDSolve[]) the system of differential equations (3.11) - (3.14) with initial values (3.15),

2. For $t=$ Oct 28th 1982, Jun 22nd 1986, Dec 17th 1989, Jun 6th 1993 and Mar 3rd 1996, corresponding to election days, evaluate the computed numerical solution for each subpopulation $E(t), N(t), V(t), A(t)$.

3. Compute the mean square error between the values obtained in Step 2 and the electoral data from Oct 28th 1982 to Mar 3rd 1996, (Table $3.1)$.

Function $\mathbb{F}$ takes values in $\mathbb{R}^{5}\left(\beta_{1}, \beta_{2}, k, \alpha_{1}\right.$ and $\left.\alpha_{2}\right)$ and returns a positive real number. Hence, we minimize this function using the Nelder-Mead algorithm $[49,55]$, that does not need the computation of any derivative or gradient, which is impossible to know in this case. Thus, the values of $\beta_{1}$, $\beta_{2}, k, \alpha_{1}$ and $\alpha_{2}$, with restrictions $0 \leq \alpha_{1}, \alpha_{2} \leq 1$ and $k>0$, that minimize the function $\mathbb{F}$ are 


$$
\begin{aligned}
& \beta_{1}=0.0534, \beta_{2}=-0.0338, \\
& k=0.5352, \\
& \alpha_{1}=0.8945, \alpha_{2}=0.9999 .
\end{aligned}
$$

Parameters indicate that population flows from $E$ to $A$ and from $A$ to $V\left(\beta_{1}, k>0\right)$, and from $A$ to $N\left(\beta_{2}<0\right)$ very slowly. Furthermore, the value of $k$ indicates that the pressure of $V$ affects twice to $E$ than to $A$. Additionally, almost all emigration and immigration occurs in subpopulation $E\left(\alpha_{1}=0.8945, \alpha_{2}=0.9999\right)$.

\subsection{Trends over next few years}

Once the model parameters have been estimated, under the assumption that government anti-terrorist policies and ETA strategies do not change, we can use the model to predict the trend of each subpopulation until 2020, i.e., the deterministic prediction. To do so, demographic data from [68] are used: immigration and emigration available data go from 1977 until 2008 and the 2008 datum is repeated until 2020; real population data from 1975 to 2008 are available and also predictions until 2020.

Then, we use the model parameters obtained in (3.16), substitute them into the model and obtain the model forecasting for next electoral years 2012 , 2016 and 2020. The results can be seen in Table 3.2.

\begin{tabular}{c|cccc} 
& $E$ & $N$ & $V$ & $A$ \\
\hline 2012 & 0.343714 & 0.291674 & 0.114067 & 0.250546 \\
2016 & 0.359023 & 0.296761 & 0.113756 & 0.23046 \\
2020 & 0.373446 & 0.302587 & 0.113205 & 0.210763
\end{tabular}

Table 3.2: Deterministic prediction for the next electoral years 2012, 2016 and 2020 .

Looking at Tables 3.1 (data from 1979 to 1996) and 3.2 jointly, we can observe a slight increase in groups $E, N$ and $V$ at the expense of $A$. It is noteworthy to see how subpopulation $V$ has hardly varied during the 40 years studied.

However, as we mentioned in the Introduction chapter, uncertainty is a key part dealing with Social Sciences phenomena. Therefore, the supposition that parameters always remain constant or data in Table 3.1 and demographic data do not contain errors, is not appropriate. Thus, it is natural to 
consider that the model parameters $\beta_{1}, \beta_{2}, k, \alpha_{1}$ and $\alpha_{2}$ contain uncertainties. Hence, the deterministic prediction can give us an idea about future trends but, in this case, the obtained values may not be accurate.

Therefore, we propose forecasting future trends using confidence intervals. In order to calculate these confidence intervals, let us use the technique called Latin Hypercube Sampling (LHS) to vary parameter values in the proposed model. LHS, a type of stratified Monte Carlo sampling, is a sophisticated and efficient method for achieving equitable sampling of all input parameters simultaneously $[14,50]$. Each parameter for a model can be defined as having an appropriate probability density function associated with it. It is usual to use the uniform distribution centred at deterministic parameter estimators in absence of data to give information as to the distribution for a given parameter $[46,50]$. Thus, the model can be simulated by sampling a single value from each parameter distribution. Many samples should be taken and many simulations should be run, producing variable output values that can be treated with descriptive statistic techniques to compute the means and $90 \%$ confidence intervals.

An important issue arises here and it is how much we should vary the parameters to quantify uncertainty. Some studies analyse the effect on populations of health campaigns [61], electoral campaigns [35] or the bombing attacks in Madrid few days before elections [7], and all of them over a short period. In these cases, what we call "effect" refers to a change of opinion to adopt a healthier way of life, to leave the abstention group and vote or to switch party. This change of opinion is about $5 \%$ in health campaigns [61], $5 \%$ - $19 \%$ in Canadian electoral campaigns depending on the time of decision [35] and around $10 \%$ in the elections immediately after attacks in Madrid [7]. Moreover, the referred changes are related to population, not to parameters and therefore, not related to rates of political ideology change. However, as we mentioned before, anti- or pro-terrorist policies and strategies are designed to change the value of the model parameters. Thus, even though we do not have any quantification of uncertainty in the parameters, let us assume that they may have a variation not greater than $20 \%$ of their values, i.e.,

$$
\begin{gathered}
\beta_{1} \in[0.0428,0.0642], \beta_{2} \in[-0.0270,-0.0406], \\
\alpha_{1} \in[0.7156,1], \alpha_{2} \in[0.78,1] .
\end{gathered}
$$

Note that $20 \%$ variation of $\beta_{1}$ implies $20 \%$ variation of $k \beta_{1}$. Now, applying the LHS technique with 5,000 samples using uniform distributions centred at the deterministic parameter values (3.16), i.e., for 5,000 different 5-tuples $\left(\beta_{1}, \beta_{2}, k, \alpha_{1}, \alpha_{2}\right)$, we solve the model to obtain 5,000 outputs 


$$
\left(E\left(t_{f}\right), N\left(t_{f}\right), V\left(t_{f}\right), A\left(t_{f}\right)\right),
$$

for $t_{f}=2012,2016,2020$, the coming electoral years. Hence, for each $t_{f}$ and for each subpopulation we can compute the $90 \%$ confidence interval from the corresponding 5,000 outputs. Results can be seen in Table 3.3 .

\begin{tabular}{c|cccc} 
& $E$ & $N$ & $V$ & $A$ \\
\hline 2012 & {$[0.261,0.37]$} & {$[0.267,0.307]$} & {$[0.109,0.124]$} & {$[0.217,0.345]$} \\
2016 & {$[0.266,0.387]$} & {$[0.268,0.315]$} & {$[0.108,0.125]$} & {$[0.196,0.337]$} \\
2020 & {$[0.271,0.404]$} & {$[0.27,0.324]$} & {$[0.107,0.126]$} & {$[0.173,0.33]$}
\end{tabular}

Table 3.3: 90\% confidence intervals obtained with 5,000 model outputs using LHS technique in the next electoral years 2012, 2016 and 2020.

The results obtained in the present section are summarised in Figure 3.5. The parts of each graph are:

- the points on the left are data from Table 3.1;

- the continuous line is the deterministic model output for parameters in (3.16);

- the $90 \%$ confidence intervals in 2012, 2016 and 2020 are on the right;

- the points in the middle of the confidence intervals are the mean of 5, 000 outputs for each subpopulation and each electoral year.

Figure 3.5 allows us to say, on the one hand, that $E$ and $A$ are the ideological groups with more uncertainty, $10.9 \%-13.3 \%$ and $12.5 \%-15.6 \%$ respectively (maximum and minimum length of their respective confidence intervals in Table 3.3), where the deterministic prediction is far from the mean of the confidence intervals. This brings up some doubts as to the deterministic prediction, to consider more conservative predictions than the one obtained with LHS one and to point out the high sensitivity of groups $E$ and $A$ to model parameter perturbations (policy changes). On the other hand, subpopulations $N$ and $V$ have few uncertainty, $4 \%-5.4 \%$ and $1.5 \%-$ $1.9 \%$ respectively, and the deterministic prediction is very close to the mean of confidence intervals. This leads us to say that there is a minor flow across groups $V$ and $N$. Even though the confidence interval variations are greater than the ones in $V$, the population in $N$ is almost three times the one in $V$ and the variation $4 \%-5.4 \%$ of $N$ is less than three times the one of $V$. It also suggests that subpopulations $N$ and $V$ are less sensitive to model parameter perturbations (policy changes). 

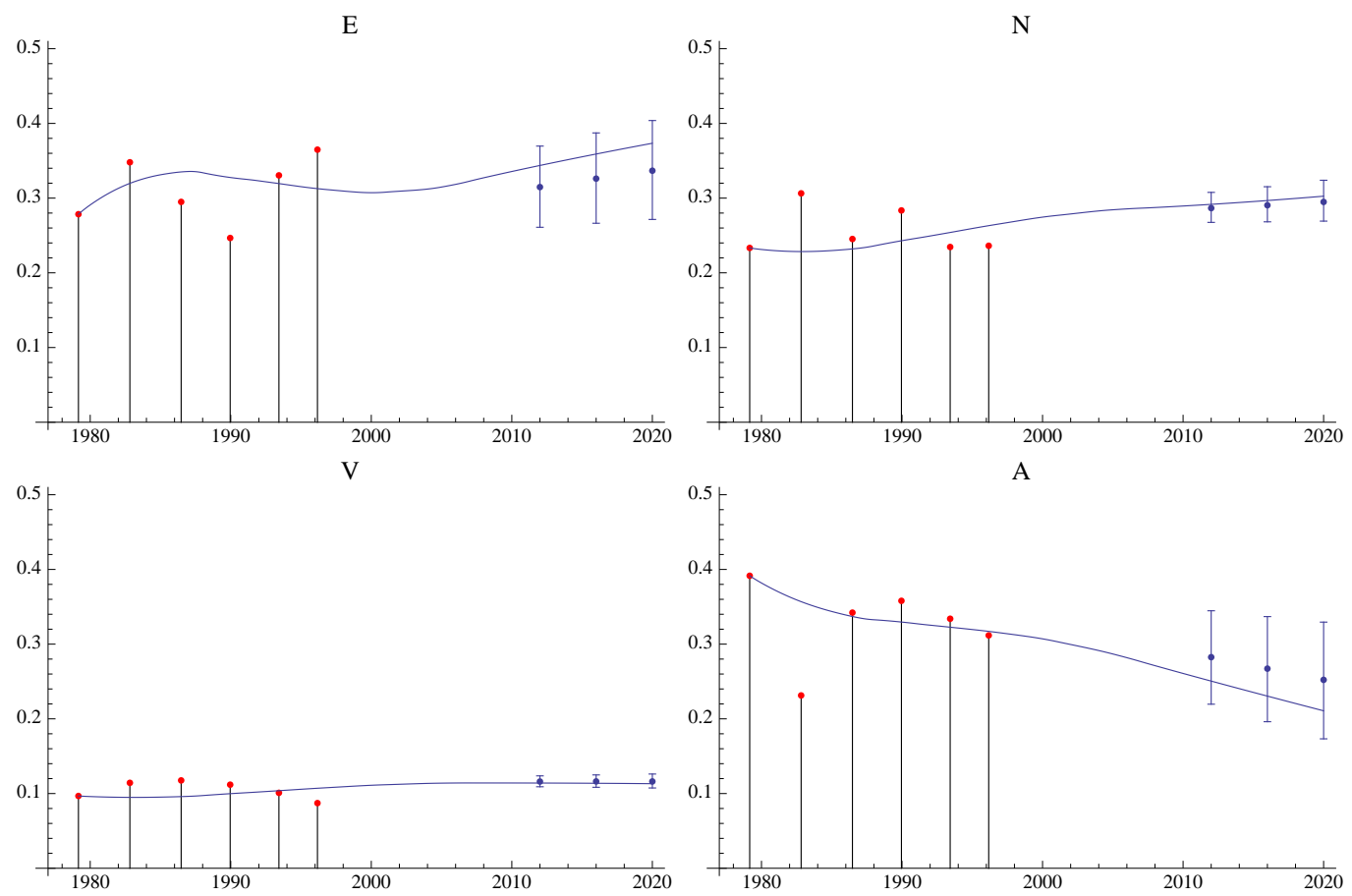

Figure 3.5: Model fitting since March 1st 1979 to March 3rd 1996 and future prediction for each subpopulation, $E, N, V$ and $A$. Points on the left are data of election days, the continuous lines the solution of the model until 2020. The $90 \%$ confidence intervals for electoral years with their mean are on the right.

\subsection{Conclusions}

In this chapter, we propose a type-epidemiological model to analyse the evolution over the time of populations in the Basque Country respect their opinions about the ETA's goals, taking into account that ETA uses violence to demand Basque independence from Spain.

Using this model and applying the Latin Hypercube Sampling, we predict ideological trends over the next few years giving $90 \%$ confidence intervals. The application of LHS is our first approach in dealing with model uncertainty, but in this case with an important drawback as is the quantification of the variation of the model parameters and the probability distribution they follow. We will attempt to overcome these inconveniences in the following chapters.

Remark. As we mentioned in the Introduction chapter, a paper including some results presented in this chapter was rejected to be published. One 
of the main drawbacks mentioned was related to the division into subpopulations, because the division was not well done and as a consequence, the predictions given in Table 3.3 are far to be correct. For instance, we predict a result of $10.9 \%-12.4 \%$ for parties in $V$ for elections in year 2012 and, as we said in Chapter 2 the parties included in $V$ obtained around $25 \%$ of votes, being the second most voted parties in the Basque Country. Moreover, an electoral prediction over the next three election dates (12 years) may be considered too long.

Therefore, although the model presented here was well considered by some referees and colleagues, it is only a rough approach to the problem. This is an example of the difficulty of modelling in Social Sciences.

However, we contacted with an expert who addressed our work and this is reflected in the following chapters. 


\section{Chapter 4}

\section{The effect of the Spanish Law of Political Parties (LPP) on the attitude of the Basque Country population towards ETA}

In Chapter 3 we presented a first approach and detected several drawbacks. With the help of the expert we focus and improve the model. Also, we use other techniques to deal with the model uncertainty in order to avoid the detected inconveniences.

As we described in Chapter 2, in Jun 2002, the Spanish Government passed the "Law of Political Parties" (LPP) with the aim, among others, to prevent parties giving political support to terrorist organizations. This law affected the Basque nationalist party Batasuna, due to its proved relation with ETA.

Along with that impact in the political arena, it is also reasonable to expect some impact in the sociological one. The question is: did the LPP have any effect on the attitude of the Basque Country population towards ETA? This question is particularly pertinent in light of the current situation in that region. On the one hand, generally speaking, it is well known that repressive initiatives taken by governments can generate sympathies, to some degree, towards the repressed organizations. On the other hand, in this particular case, violent activities carried out by ETA could be responsible for part of the population not expressing their political beliefs freely, so measures taken to prevent ETA's violence could encourage people to express themselves more openly. In other words, either has ETA together with its political wings, 
gained additional support from the population or has part of the Basque country been uninhibited because of that law?

In order to study this problem, we use a new data set from the Euskobarometro survey [33, Table 20], one of the best-known independent opinion polls in the region, which is periodically conducted by the University of the Basque Country. The period of time considered for this study is from the passing of the LPP (Jun 2002) to May 2005. The reason for this time limitation is that, in our opinion, during this period the anti-terrorist policies were reasonably homogeneous, while, from May 2005 on, a perceptible change occurred when the Congress approved the possibility the Government supports a dialogue process with ETA given that appropriate conditions to end violence occur [15, Resolución 34, p. 13]. It is believed that this major event, and subsequent ones as well, could jeopardize the homogeneity necessary to conduct this study ${ }^{1}$. Finally, remark that during the mentioned period of time, the 11-M bombing attacks in Madrid (on 11 March 2004), did not provoke major changes in the trend. We justified this in Chapter 2.

This chapter is organized as follows. In Section 4.1, data from Euskobarometro about the attitude of the Basque Country population towards ETA are retrieved and processed [33, Table 20]. Section 4.2 is devoted to building a model describing the attitude dynamics towards ETA in the Basque Country. Model parameters are estimated in Section 4.3 by fitting the model with the Euskobarometro data. In Section 4.4 it is concluded that the LPP is responsible for an increasing attitude of rejection towards ETA and we quantify this effect by using a bootstrapping approach. Finally, some conclusions are drawn in Section 4.5.

\subsection{Data}

In this case we are not going to use electoral data. Instead, we use data series from Euskobarometro. This was suggested by the expert because Euskobarometro appears every six months (is more regular) and it asks for a lot of relevant sociological and political questions in the Basque Country. Furthermore, when an individual vote to a political party, he/she does not necessarily assume and support all the ideas of the political party.

Thus, we have retrieved data series from the Euskobarometro of Nov 2010 on the attitude of the Basque Country population towards ETA [33, Table 20]. The eight types of attitudes towards ETA that appear in the

\footnotetext{
${ }^{1}$ A month later, ETA announced the cessation of its armed actions against the elected politicians in Spain, although later on it pointed out that this truce did not apply to members of the Government.
} 
Euskobarometro are as follows: Total support; Justification with criticism; Goals yes / Means no; Before yes / Not now; Indifferent; ETA scares; Total rejection; No answer. In order to simplify the model (the number of subpopulations) we group the eight attitudes in only three.

1. Support: people who have an attitude of support towards ETA. We consider the people with attitudes of "Total support" and "Justification with criticism" make up of this group.

2. Rejection: people who have an attitude of rejection against ETA. In this group we include the people with attitudes "Goals yes / Means no", "Before yes / Not now", "ETA scares" and "Total rejection". It could be questionable to include in this group the attitude "Goals yes / Means no", however, the fact is that there are parties and associations in the Basque Country with similar goals as ETA and they have a rejection attitude towards ETA because of its violent means.

3. Abstention: people who have no opinion or have an indifferent attitude towards ETA, that is, the "Indifferent" and the "No answer" groups.

Data grouped in these three groups appear in Table 4.1 from May 1995 to May 2002 (before the passing of the LPP) and Table 4.2 for the period from Nov 2002 to May 2005 (after the passing of the LPP until the granting of permission by the Spanish Parliament to conduct a dialogue with ETA).

\begin{tabular}{|l|c|c|c|}
\hline Survey date & Support (\%) & Rejection (\%) & Abstention (\%) \\
\hline May 1995 & 7 & 85 & 8 \\
Nov 1995 & 5 & 87 & 8 \\
Nov 1996 & 6 & 87 & 7 \\
Nov 1997 & 6 & 86 & 8 \\
Nov 1998 & 5 & 85 & 10 \\
May 1999 & 11 & 76 & 13 \\
May 2000 & 8 & 87 & 5 \\
Nov 2000 & 7 & 87 & 6 \\
May 2001 & 3 & 90 & 7 \\
Nov 2001 & 4 & 88 & 8 \\
May 2002 & 2 & 96 & 2 \\
\hline
\end{tabular}

Table 4.1: Percentage of people in the Basque Country with respect to their attitude towards ETA from May 1995 to May 2002, when the LPP was passed (pre-LPP scenario). 


\begin{tabular}{|l|c|c|c|}
\hline Survey date & Support (\%) & Rejection (\%) & Abstention (\%) \\
\hline Nov 2002 & 3 & 93 & 4 \\
May 2003 & 2 & 95 & 3 \\
Nov 2003 & 2 & 94 & 4 \\
May 2004 & 3 & 93 & 4 \\
Nov 2004 & 3 & 93 & 4 \\
May 2005 & 2 & 93 & 5 \\
\hline
\end{tabular}

Table 4.2: Percentage of people in the Basque Country with respect to their attitude towards ETA from Nov 2002 to May 2005, after the passing of the LPP until the granting of the permission by the Spanish Parliament to conduct a dialogue with ETA (post-LPP scenario).

The data in Table 4.1 will help us to estimate the parameters of the mathematical model. The data in Table 4.2 will be used to find out if the LPP affected the attitude of the people in the Basque Country towards ETA, and if so, quantify the effect of the LPP.

\subsection{Model building}

Bearing in mind Tables 4.1 and 4.2, we distinguish three main different attitudes towards ETA and divide the population of the Basque Country into the following three subpopulations (time $t$ in years):

- $A_{1}(t)$, the percentage of people in the Basque Country who have an attitude of support towards ETA at time instant $t$,

- $A_{2}(t)$ is the percentage of people who have an attitude of rejection towards ETA at time $t$,

- $A_{3}(t)$ corresponds to the percentage of population in the Basque Country whose attitude towards ETA is not defined, who abstain, or who simply do not want to state their opinion, at time $t$.

$A_{1}(t), A_{2}(t)$ and $A_{3}(t)$ are the variables of the mathematical model. The assumptions used to build the equations of the model are as follows.

- A subpopulation $A_{i}$, whose people share a particular attitude towards a phenomenon, can influence the attitude of people of another subpopulation, $A_{j}$, towards the same phenomenon. This influence can be provoked either by direct contact, i.e., when people from $A_{i}$ and $A_{j}$ interact, or by indirect contact, i.e., through the interaction of a person in $A_{i}$ with his/her environment. 
- Regarding this latter way, in this context, it is assumed that the environment of a person in $A_{j}$ is made up of the flows and channels of information able to reach his/her sensorial system. Note that reaching a sensorial system does not imply necessarily reaching perception. Thus, alteration in that environment can provoke either changes in the attitude of that person in $A_{j}$ or not. Environment alteration can be provoked, in its turn, by the behaviour of people from the other subpopulations among other factors, attitude being itself considered as a part of that behaviour.

- It is assumed that all people could access to all relevant information channels and flows, i.e., there is in principle a homogeneous environment affecting people of all the subpopulations. However, the interaction of a person with the environment varies on an individual basis, depending on both situational and non-situational factors. The individual initial attitude itself towards the subject of influence, for instance, is a non-situational factor which modulates environment influence, acting on that initial attitude either as an enabler or as a shield.

- It is not the goal of this work to clarify those factors of variation, but only to show the eventual changes in attitudes of the target populations and, if possible, to attribute those changes to the influence of other subpopulations, either directly or indirectly. However, a diffuse idea about the involved processes, environment effectiveness differences etc., as a whole, can be obtained from the model. The non linear term $\beta_{i j} A_{i} A_{j}$ is the term that models these influences, it is the parameter $\beta_{i j}$ that, in some way, measures that environment effectiveness and includes the rest of the above-mentioned factors.

The system of differential equations that models the evolution of attitudes towards ETA in Basque Country over time is given by

$$
\begin{aligned}
& A_{1}^{\prime}(t)=\left(\beta_{21}-\beta_{12}\right) A_{2}(t) A_{1}(t)+\left(\beta_{31}-\beta_{13}\right) A_{3}(t) A_{1}(t), \\
& A_{2}^{\prime}(t)=\left(\beta_{12}-\beta_{21}\right) A_{2}(t) A_{1}(t)+\left(\beta_{32}-\beta_{23}\right) A_{3}(t) A_{2}(t), \\
& A_{3}^{\prime}(t)=\left(\beta_{13}-\beta_{31}\right) A_{3}(t) A_{1}(t)+\left(\beta_{23}-\beta_{32}\right) A_{3}(t) A_{2}(t) .
\end{aligned}
$$

The above system of differential equations can be represented by the diagram given as Figure 4.1.

This new model has the advantge, if we compare it to the one in Chapter 3 , that it is directly related to the opinion of the people, not via the political parties they vote. 


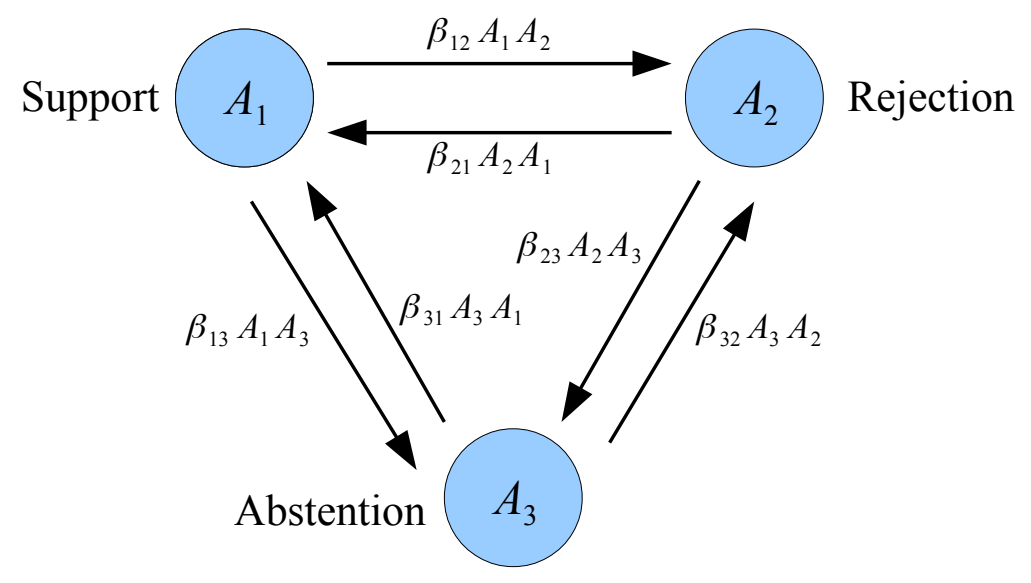

Figure 4.1: Graph depicting the model (4.1)-(4.3). Circles are the subpopulations and arrows represent the flow of people who change their attitude towards ETA over time.

\subsection{Estimation of model parameters}

The model has six unknown parameters $\beta_{i j}, i, j=1,2,3, i \neq j$, and we should estimate them taking into account that the model has to be as close as possible to data in Table 4.1, that is, before the passing of the LPP.

To do that, we adapted the algorithm used in Chapter 3, implemented in Mathematica [45], in order to compute the parameters which best fit the model with the data of Table 4.1 in the least square sense. The values of these parameters appear in Table 4.3.

\begin{tabular}{|cc|ccc|}
\hline Parameter & Value & & Parameter & Value \\
\hline$\beta_{12}$ & 0.0815425 & & $\beta_{21}$ & 0.0627668 \\
$\beta_{13}$ & 0.000421055 & $\beta_{31}$ & 0.182483 \\
$\beta_{23}$ & 0.0317568 & & $\beta_{32}$ & 0.0216873 \\
\hline
\end{tabular}

Table 4.3: Estimated model parameters.

We can see the fitting graphically in the Figure 4.2.

\subsection{Analysis of the effect of the LPP}

In Figure 4.3, we can see the model predictions (line) for every subpopulation after LPP passing (Jun 2002) until May 2005 and data from Table 4.2 

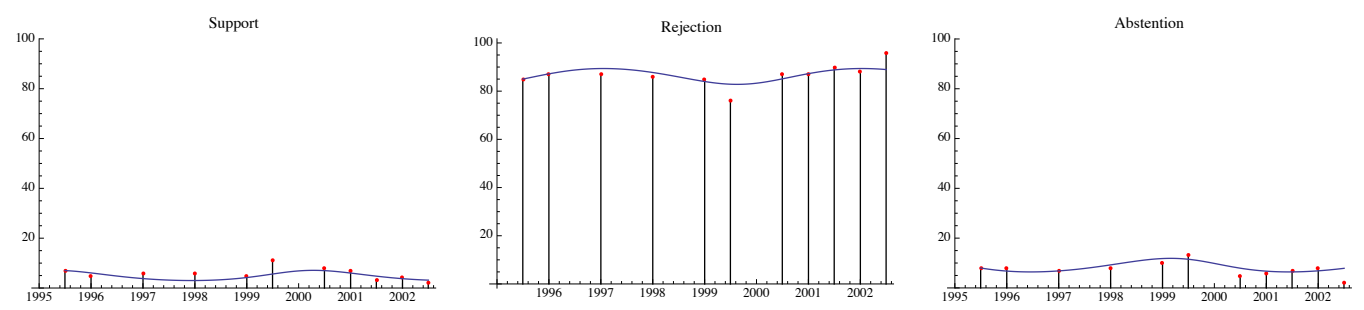

Figure 4.2: Graph representing the fitting. The lines are the corresponding model functions and the points are data from Table 4.1. Support subpopulation $A_{1}(t)$ on the left, Rejection subpopulation $A_{2}(t)$ in the middle, and Abstention subpopulation $A_{3}(t)$ on the right.

(points).
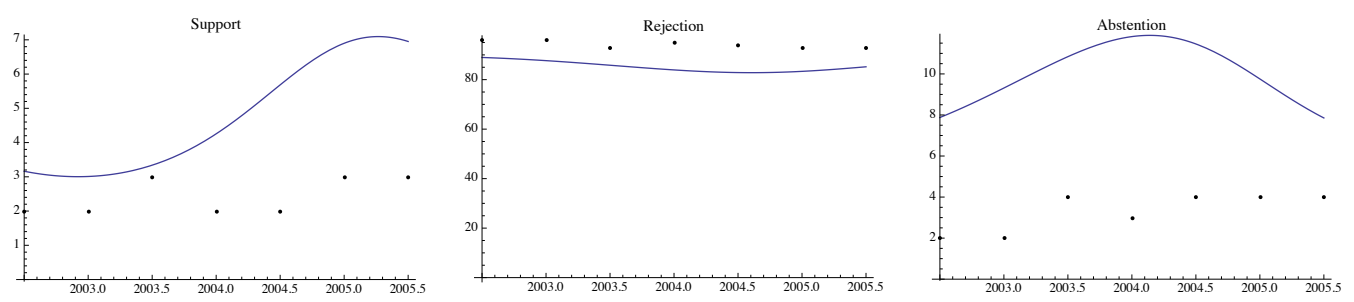

Figure 4.3: Graph of model prediction after LPP (Jun 2002) until May 2005 (line) with data from Table 4.2 (points). The question is if the differences are due to model-fitting errors (non-significant) or are due to the LPP (significant).

Looking at the graph (Figure 4.3), it is difficult to say if the differences between the points and the model prediction, on one hand, are attributable to model-fitting errors, i.e., the differences are non-significant and consequently the LPP did not have effect on the general attitude towards ETA, or, on the other hand, if the differences are significant and attributable to the LPP.

\subsubsection{Finding out if the differences between the data and the model prediction are (or are not) due to the effect of the LPP on the Basque population?}

An uncertainty study of the predictions of the model will allow us to determine if differences between the data and the model prediction are significant. Thus, in order to obtain more information on the output of the mathematical 
model, we use a residual bootstrapping approach. Considering the general procedure presented by Dogan in [27], we study error terms for the estimated parameters and resample these terms using bootstrapping. Then, we obtain new perturbed data by adding the resampled error to Table 4.1 data. For each new data perturbation calculated, we compute the parameters that best fit the model with the perturbed dataset. Once we compute the set of parameter values obtained by fitting the model with the perturbed data, we solve the model with these parameters and compute the outputs in the required time instants. Taking the $90 \%$ confidence interval of each output from each subpopulation by percentile 5 and percentile 95 and comparing with the corresponding datum from Table 4.2, i.e., if the datum lies inside the confidence interval or not, we will be able to conclude if the LPP had effect on the attitude of Basque population towards ETA or not, and to quantify it by measuring the distance of the datum to the extremes of the confidence interval.

\subsubsection{Error term analysis}

First, we compute the output of the model with the parameters in Table 4.3 in the time instants appearing in Table 4.1 (from May 2005 to May 2002) and compute their differences with the corresponding data from Table 4.1. The results can be seen in Table 4.4 .

\begin{tabular}{|cccc|}
\hline Survey date & $A_{1}(t)-\hat{A}_{1}(t)$ & $A_{2}(t)-\hat{A}_{2}(t)$ & $A_{3}(t)-\hat{A}_{3}(t)$ \\
\hline Nov $1995(\mathrm{t}=1)$ & -1.060970135 & -0.172986635 & 1.23395677 \\
Nov $1996(\mathrm{t}=2)$ & 2.216235209 & -2.382102564 & 0.165867355 \\
Nov $1997(\mathrm{t}=3)$ & 2.992820716 & -1.740283841 & -1.252536874 \\
Nov $1998(\mathrm{t}=4)$ & 0.792540417 & 1.008587701 & -1.801128118 \\
May $1999(\mathrm{t}=5)$ & 5.386657918 & -6.874217326 & 1.487559407 \\
May 2000 $(\mathrm{t}=6)$ & 1.02135272 & 1.909570229 & -2.930922949 \\
Nov 2000 $(\mathrm{t}=7)$ & 0.993820922 & -0.260804633 & -0.733016289 \\
May 2001 $(\mathrm{t}=8)$ & -1.762253593 & 1.194714054 & 0.567539539 \\
Nov 2001 $(\mathrm{t}=9)$ & 0.250086725 & -1.385370292 & 1.135283566 \\
May 2002 $(\mathrm{t}=10)$ & -1.164726381 & 7.035272584 & -5.870546202 \\
\hline
\end{tabular}

Table 4.4: Residual or error terms. $A_{i}(t)$ are the real data (Table 4.1) and $\hat{A}_{i}(t)$ are the predictions of the model.

Now, we analyse whether the error terms $e_{1 t}=A_{1}(t)-\hat{A}_{1}(t), e_{2 t}=$ $A_{2}(t)-\hat{A}_{2}(t)$ and $e_{3 t}=A_{3}(t)-\hat{A}_{3}(t)$ are correlated. The Pearson correlation coefficient is used, and the results obtained are as follows: $\rho_{12}=-0.782$, 
$p$-value $=0.007 ; \rho_{13}=0.270, p$-value $=0.4514 ; \rho_{23}=-0.811, p$-value $=$ 0.004. Note that $\rho_{i j}$ is the Pearson correlation coefficient between $e_{i t}$ and $e_{j t}$. Therefore, there is dependence between the errors.

Taking into account runs test, we also study if each error term is autocorrelated. Note that this non-parametric test can be used to check the hypothesis that the elements of a sequence are mutually independent. In this case, the results are as follows: $z_{1}=1.677, p-$ value $=0.094 ; z_{2}=-0.335$, $p-$ value $=0.737 ;$ and $z_{3}=0.000, p-$ value $=1.000$. None of the test statistic values is statistically significant $(p-$ value $>0.05)$; therefore the claim that there is autocorrelation should be rejected. $z_{i}$ is the runs test statistic value for each case.

Additionally, the normality of the distribution of errors is determined by using non-parametric tests. A goodness-of-fit analysis suggests that each error term is normally distributed. The Kolmogorov-Smirnov and ShapiroWilk tests have $p$-values of $0.200,0.200,0.200$ and $0.560,0.552,0.154$, respectively. Moreover, Mardia's multivariate normality test is applied to the sample $\left(e_{1 t}, e_{2 t}\right), t=0,1, \ldots, 10$ (see Table 4.4). In this case, Mardia's test has a $p$-value equal to $0.282(p-$ value $>0.05)$. Therefore, we can accept that vector $\left(e_{1 t}, e_{2 t}\right)$ presents a bivariate normal distribution. To be precise, we accept that

$$
\left(e_{1 t}, e_{2 t}\right) \sim N_{2}\left[\left(\begin{array}{c}
\mu_{e_{1 t}} \\
\mu_{e_{2 t}}
\end{array}\right),\left(\begin{array}{cc}
\sigma_{e_{1 t}}^{2} & \rho_{12} \sigma_{e_{1 t}} \sigma_{e_{2 t}} \\
\rho_{12} \sigma_{e_{1 t}} \sigma_{e_{2 t}} & \sigma_{e_{2 t}}^{2}
\end{array}\right)\right]
$$

where $\mu_{e_{i t}}$ and $\sigma_{e_{i t}}, i=1,2$, are the mean and the standard deviation of $e_{i t}$, respectively, and $\rho_{12}$ is the Pearson correlation coefficient between $e_{1 t}$ and $e_{2 t}$. These parameters can be estimated using the errors in Table 4.4 and the values are $\mu_{e_{1 t}}=0.966556, \mu_{e_{2 t}}=-0.166762, \sigma_{e_{1 t}}=2.15643, \sigma_{e_{2 t}}=$ 3.54782 and $\rho_{12}=-0.738104$. Finally, considering that $e_{1 t}+e_{2 t}+e_{3 t}=0$, $t=1, \ldots, 10, e_{3 t}$ can be calculated by $e_{3 t}=-e_{1 t}-e_{2 t} . e_{1 t}$ and $e_{2 t}$ are estimated by (4.4).

\subsubsection{Generating new perturbed data}

Bearing in mind data from Table 4.1 (pre-LPP data), for $t=$ May 1995, Nov $1995, \ldots$. May 2002 , we generate 10 random pairs $\left(e_{1 t}, e_{2 t}\right)$ following the multivariate distribution given by the expression (4.4) and $e_{3 t}$ as $e_{3 t}=$ $-e_{1 t}-e_{2 t}$. Thus, we have 10 vectors $\left(e_{1 t}, e_{2 t}, e_{3 t}\right)$ for $t=$ May 1995, Nov $1995, \ldots$. May 2002, and we add them to data in Table 4.1, obtaining a new set of perturbed data. Then, we compute the parameters which best fit the model with the new set of perturbed data in the least square sense and store 
them, using the same procedure we used to estimate the parameters of Table 4.3 .

We repeat this procedure 5000 times in order to obtain 5000 sets of parameters that fit each set of perturbed data (pre-LPP data plus $\left(e_{1 t}, e_{2 t}, e_{3 t}\right)$ for each $t$ ).

\subsubsection{Obtaining confidence intervals for model outputs}

For each one of the 5000 set of parameters, we solve the system of differential equations (4.1)-(4.3) and compute the output of the solution, i.e., in the three subpopulations $A_{1}(t), A_{2}(t)$ and $A_{3}(t)$, for $t=$ Nov 2002, May 2003, Nov 2003, May 2004, Nov 2004 and May 2005 (post-LPP data). Thus, for each $t$, and for each subpopulation, we have a set of 5000 model output values. Then, we compute the mean and the $90 \%$ confidence interval (CI) by percentiles 5 and 95. The results obtained can be seen in Table 4.5.

\begin{tabular}{|l|cc|cc|cc|}
\hline & \multicolumn{2}{|c|}{ Support } & \multicolumn{2}{c|}{ Rejection } & \multicolumn{2}{c|}{ Abstention } \\
\hline & Mean & $90 \%$ CI & Mean & $90 \%$ CI & Mean & $90 \%$ CI \\
\hline Nov 2002 & 4.595 & {$[2.387,7.978]$} & 86.643 & {$[83.893,89.018]$} & 8.762 & {$[7.031,10.831]$} \\
May 2003 & 5.310 & {$[2.673,9.912]$} & 85.144 & {$[82.737,87.470]$} & 9.546 & {$[6.546,12.453]$} \\
Nov 2003 & 6.161 & {$[3.421,10.514]$} & 84.180 & {$[81.800,86.306]$} & 9.660 & {$[4.753,13.634]$} \\
May 2004 & 6.791 & {$[4.549,9.627]$} & 84.099 & {$[80.615,87.984]$} & 9.110 & {$[3.774,13.699]$} \\
Nov 2004 & 7.021 & {$[5.673,8.509]$} & 84.839 & {$[80.374,89.566]$} & 8.141 & {$[3.577,12.839]$} \\
May 2005 & 6.755 & {$[5.117,8.218]$} & 85.967 & {$[80.931,90.410]$} & 7.278 & {$[3.949,11.225]$} \\
\hline
\end{tabular}

Table 4.5: Means and 90\% confidence intervals of the model output. We estimate these predictions (point prediction and interval prediction) solving the model (4.1)-(4.3) for each one of the 5000 sets of parameters calculated by fitting the model with the perturbed pre-LPP data.

In Figure 4.4 we can see graphically, for each subpopulation, the data from Table 4.1 to Table 4.2 (points), the deterministic model prediction (line) and the $90 \%$ confidence intervals (error bars). The points in the middle of the confidence intervals are the means of 5000 outputs for each subpopulation and each time instant where we have data about attitudes towards ETA. These mean values are those appearing in Table 4.5.

If we observe the right-hand side of the vertical axis in the three graphs, we realise two facts: on the one hand, there are differences between the deterministic model predictions and the means of Table 4.5. These differences indicate that the model is sensitive to parameter changes; on the other hand, most of the attitude prevalence points lie out of their corresponding $90 \%$ confidence intervals, and those that lie inside are placed in the interval extremes. This leads us to say that the LPP had effect on the attitude of the 

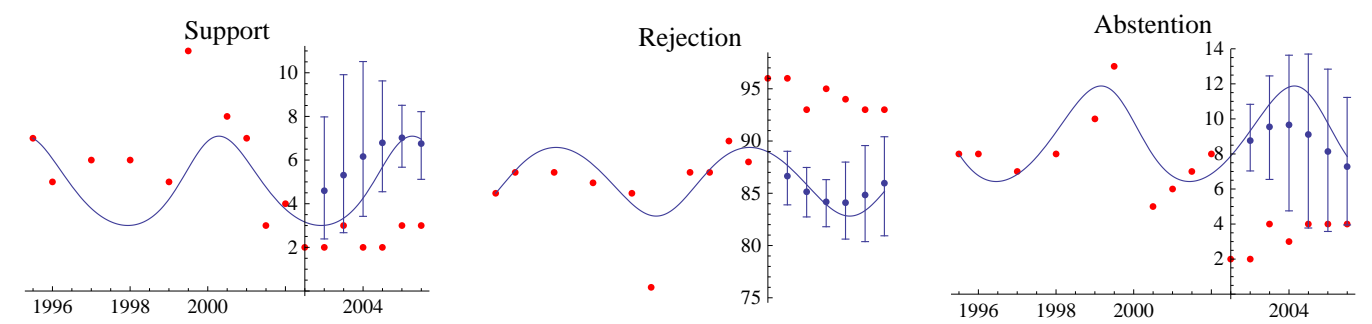

Figure 4.4: In this graph we show the attitude towards ETA (points), the model deterministic prediction (line) and the error bars corresponding to $90 \%$ confidence intervals in the same time instants as we have data in Tables 4.1 and 4.2. The points inside the confidence intervals are the mean of the 5000 outputs for every subpopulation in every time instant. The vertical axis is placed on the time instant when the LPP was passed (Jun 2002).

Basque population towards ETA. Moreover, we can see that, around the 11M bombing attacks in Madrid, the points still lie outside of the confidence intervals, and this fact leads us to give another reason on that the Madrid attacks had hardly any effect on the general attitude of the Basque Country population towards ETA.

In Table 4.6, we show the differences between the attitude data (Table 4.1) and their corresponding 90\% interval extremes (Table 4.5), in order to obtain an upper and lower bound measurement of the LPP effect on the Basque population.

\begin{tabular}{|c|ccc|}
\hline & Support & Rejection & Abstention \\
\hline Nov 2002 & {$[0.39,5.98]$} & {$[6.98,12.11]$} & {$[5.03,8.83]$} \\
May 2003 & {$[-0.33,6.91]$} & {$[5.53,10.26]$} & {$[2.55,8.45]$} \\
Nov 2003 & {$[1.42,8.51]$} & {$[8.69,13.20]$} & {$[1.75,10.63]$} \\
May 2004 & {$[2.55,7.63]$} & {$[6.02,13.38]$} & {$[-0.23,9.70]$} \\
Nov 2004 & {$[2.67,5.51]$} & {$[3.43,12.63]$} & {$[-0.42,8.84]$} \\
May 2005 & {$[2.12,5.22]$} & {$[2.59,12.07]$} & {$[-0.05,7.22]$} \\
\hline
\end{tabular}

Table 4.6: Distances between Table 4.2 data and the extremes of their corresponding $90 \%$ confidence intervals. Intervals with negative values mean that the attitude prevalence datum lies inside the $90 \%$ confidence interval.

Looking at Figure 4.4 and Table 4.6, we can conclude that the LPP had an effect on increasing the number of people who have an attitude of rejection towards ETA at the expense to the ones who previously have an attitude of support or abstention. Moreover, the increase is strong until Nov 2003 - May 
2004 (minimum of $8.69 \%$ and maximum of $13.38 \%$ ), when, even maintaining values greater than before the law was passed, the trend starts to decrease slightly.

\subsection{Conclusion}

In this chapter, we present a mathematical model to study the evolution dynamics of the attitude of Basque population towards ETA. Once the model is stated, we determine the model parameters in such a way that the model is able to fit the data from Table 4.1.

Then, we use it to find out if the LPP had any effect on changing the attitude of the Basque population towards ETA over the time after its passing. To do that, we use a residual bootstrapping approach to get more information about the estimated parameter values and to obtain output model values. With these outputs, we calculated confidence intervals that allowed us to determine if the differences between Table 4.2 data and model outputs are related to intrinsic model errors or LPP's effect. The use of a residual bootstrapping technique has improved the model uncertainty treatment. However, we must say that during its application we realised that, to be applied, it has to fulfill restrictive hypotheses and it does not consider the uncertainty in the initial condition. Therefore, we will attempt to avoid the mentioned inconveniences in the next chapter.

As we can see from the results, there is a clear effect of the LPP in the time interval May 2002 until May 2005, where the Rejection attitude increases strongly until Nov 2003 - May 2004 (minimum of $8.69 \%$ and maximum of $13.38 \%$ ) and then, a slight decrease, maintaining values greater than those before the passing of the LPP during the whole period. These greater values of the Rejection subpopulation are at the expense of the other subpopulations, Support and Abstention. The 11-M bombing attacks in Madrid, in Mar 2004, could have had some local impact in the polls, but they do not interfere in the general trend.

Therefore, the effect of the LPP, for Rejection subpopulation, can be measured from May 2002 to May 2005 as an increase of $2.59 \%$ in the lower case and an increase of $13.38 \%$ in the higher case of the people changing to a rejection attitude towards ETA (see Table 4.6).

Note that, in this chapter, we have stated an improved model and the uncertainty has been studied using a bootstrapping technique and we could to quantify the effect of the LPP.

Finally, as we mentioned in Chapter 1, nowadays, there are important political parties, mass media and organizations supporting the negotiation 
with ETA as the best choice to finish with its activities. However, this chapter supports that the opposite idea may be possible, that is, the appropriate use of the laws is an useful tool to fight against these extreme organizations and change the citizen's mind against their social pressure. 


\section{Chapter 5}

\section{A probabilistic estimation and prediction technique for the evolution of the attitude of the Basque Country population towards ETA}

This chapter is twofold: on the one hand we are going to use the model developed in Chapter 4 to predict the evolution dynamics of the attitude of Basque population towards ETA over the next few years in order to know if the Supporters, the source of ETA members, decrease or not; on the other hand, we introduce a new technique to deal with uncertainty, avoiding some inconveniences detected in the previous chapters, that allows us to give the predictions using confidence intervals.

Thus, here we propose a computational approach where the data, retrieved from surveys, play a fundamental role to introduce the uncertainty, in estimation and prediction, from the very beginning.

The chapter is organized as follows. In Section 5.1, we summarize the model building presented in Chapter 4 introducing some variations and the Euskobarometro data since May 2005. In Section 5.2 we propose a technique which will allow us to obtain a set of model parameters that provide $95 \%$ confidence intervals for each time instant such that the data uncertainty is captured. We will call this technique probabilistic estimation. With the set of parameters obtained in Section 5.2, in Section 5.3 we obtain a probabilistic prediction of the attitude towards ETA of the people of the Basque Country over the next four years. In Section 5.4, we discuss the results and present the conclusion. 


\subsection{Data and model}

In Section 4.1 we retrieved data series from the Euskobarometro of November 2012 on the attitude of the Basque Country population towards ETA [33, Table 20]. We gathered the eight different attitudes in only three as we did in the Chapter 4. Data grouped in these three groups appear, in percentages, in Figures 2.1, 2.2 and 2.3 from May 1995 until Nov 2012. In May 2005 the Spanish Parliament approved the possibility the Government to support dialogue with ETA, what has been considered as a substantial change in the anti-terrorist policy. This policy is still in force and it justifies that we choose this time instant as our model's initial condition. In Table 5.1 we present the figures in percentages of each subpopulation from May 2005 to Nov 2012.

\begin{tabular}{|l|c|c|c|}
\hline Survey date & Support (\%) & Rejection (\%) & Abstention (\%) \\
\hline May 05 & 2 & 93 & 5 \\
Nov 05 & 3 & 93 & 4 \\
May 06 & 3 & 93 & 4 \\
Nov 06 & 4 & 86 & 10 \\
May 07 & 2 & 84 & 14 \\
Nov 07 & 2 & 90 & 8 \\
May 08 & 3 & 90 & 7 \\
Nov 08 & 1 & 93 & 6 \\
May 09 & 4 & 90 & 6 \\
Nov 09 & 3 & 89 & 8 \\
May 10 & 3 & 90 & 7 \\
Nov 10 & 4 & 88 & 8 \\
May 11 & 4 & 90 & 6 \\
Nov 11 & 3 & 89 & 8 \\
May 12 & 5 & 89 & 6 \\
Nov 12 & 3 & 92 & 5 \\
\hline
\end{tabular}

Table 5.1: Percentage of people in the Basque Country with respect to their attitude towards ETA from May 2005 to Nov 2012.

In Section 4.2, we introduced the following system of nonlinear differential equations to describe the evolution of the attitudes towards ETA in the Basque Country over time:

$A_{1}^{\prime}(t)=\beta_{21} A_{2}(t) A_{1}(t)-\beta_{12} A_{1}(t) A_{2}(t)+\beta_{31} A_{3}(t) A_{1}(t)-\beta_{13} A_{1}(t) A_{3}(t)$,

$A_{2}^{\prime}(t)=\beta_{12} A_{1}(t) A_{2}(t)-\beta_{21} A_{2}(t) A_{1}(t)+\beta_{32} A_{3}(t) A_{2}(t)-\beta_{23} A_{2}(t) A_{3}(t)$,

$A_{3}^{\prime}(t)=\beta_{13} A_{1}(t) A_{3}(t)-\beta_{31} A_{3}(t) A_{1}(t)+\beta_{23} A_{2}(t) A_{3}(t)-\beta_{32} A_{3}(t) A_{2}(t)$. 
Taking $\gamma_{12}=\beta_{12}-\beta_{21}, \gamma_{13}=\beta_{13}-\beta_{31}$ and $\gamma_{23}=\beta_{23}-\beta_{32}$, the above system can be simplified as follows

$$
\begin{aligned}
& A_{1}^{\prime}(t)=-\gamma_{12} A_{2}(t) A_{1}(t)-\gamma_{13} A_{3}(t) A_{1}(t) \\
& A_{2}^{\prime}(t)=\gamma_{12} A_{2}(t) A_{1}(t)-\gamma_{23} A_{3}(t) A_{2}(t) \\
& A_{3}^{\prime}(t)=\gamma_{13} A_{3}(t) A_{1}(t)+\gamma_{23} A_{3}(t) A_{2}(t)
\end{aligned}
$$

Note that if $\gamma_{i j}>0$ the net movement of individuals is from $A_{i}$ to $A_{j}$. The above system of differential equations can be represented by the diagram of Figure 5.1.

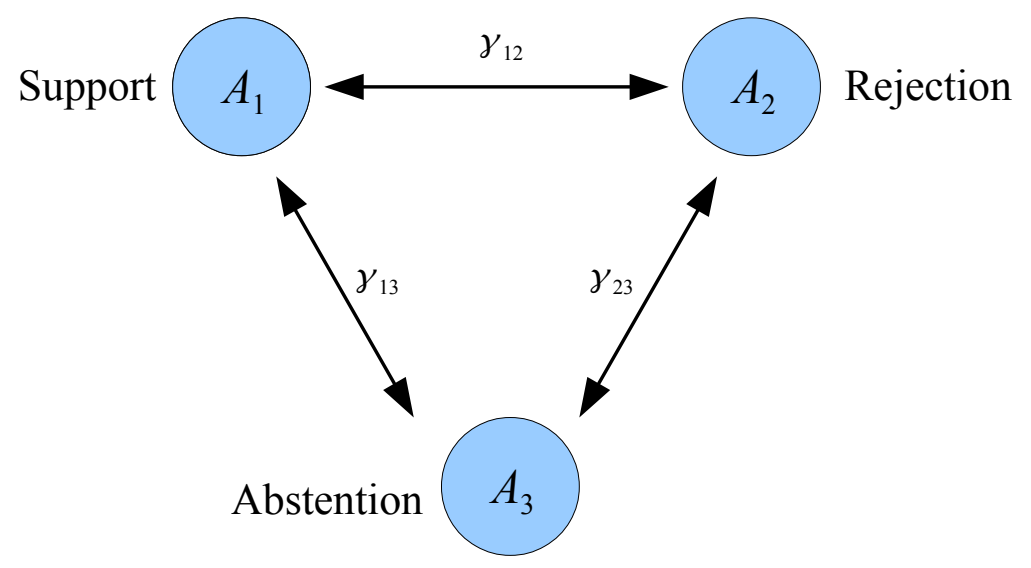

Figure 5.1: Graph depicting the model (5.1)-(5.3). The circles are the subpopulations and the arrows represent the flow of people who change their attitude towards ETA over the time.

\subsection{Probabilistic estimation: A computational technique to determine the empirical prob- abilistic distribution of model parameters}

Roughly, this technique can be summarised in the following steps:

1. Assuming a probability distribution for every survey, determine data survey confidence intervals. 
2. Use the survey probability distributions to sample data (survey simulations) a large number of times, and we obtain the model parameters that make the model fits the sampled data.

3. Among the obtained sets of model parameters, select the ones for which the model output confidence intervals computed substituting all of them into the model and solving it, are as close as possible of the data survey confidence intervals.

Now, we are going to describe it in detail.

\subsubsection{Data}

Data in Table 5.1 correspond to the mean percentage obtained from the Euskobarometro surveys since May 2005 to Nov 2012 [33, Table 20]. In the technical specifications of each survey we can see sample sizes of 1800 and 1200 interviews (see column 3 in Table 5.2).

Taking into account that the sample is not the same for each survey, let us assume that the survey outputs are independent. For each one of the 16 available surveys, let us denote by $X^{j}=\left(X_{1}^{j}, X_{2}^{j}, X_{3}^{j}\right), 0 \leq X_{i}^{j} \leq n_{j}$, $i=1,2,3, j=1, \ldots, 16$, a random vector whose entries are $X_{1}^{j}=$ Support, $X_{2}^{j}=$ Rejection, $X_{3}^{j}=$ Abstention and $n_{j} \in\{1200,1800\}$ is the sample size of survey $j$. These components represent exclusive selections (events) with probabilities

$$
P^{j}\left(X_{1}^{j}=x_{1}\right)=\theta_{1}^{j}, P^{j}\left(X_{2}^{j}=x_{2}\right)=\theta_{2}^{j}, P^{j}\left(X_{3}^{j}=x_{3}\right)=\theta_{3}^{j}, j=1, \ldots, 16,
$$

where $\theta_{1}^{j}, \theta_{2}^{j}$ and $\theta_{3}^{j}$ are the percentages collected in Table 5.1 for each survey $j, j=1, \ldots, 16$. We have accepted that each random vector $X^{j}$ follows a multinomial (trinomial) probability distribution. Therefore, the probability that $X_{1}^{j}$ occurs $x_{1}$ times, $X_{2}^{j}$ occurs $x_{2}$ times and $X_{3}^{j}$ occurs $x_{3}$ times is given by

$$
P_{n_{j}}^{j}\left(x_{1}, x_{2}, x_{3}\right)=\frac{n_{j} !}{x_{1} ! x_{2} ! x_{3} !}\left(\theta_{1}^{j}\right)^{x_{1}}\left(\theta_{2}^{j}\right)^{x_{2}}\left(\theta_{3}^{j}\right)^{x_{3}}, j=1, \ldots, 16,
$$

where $x_{1}+x_{2}+x_{3}=n_{j}$. The resulting trinomials for each Euskobarometro survey can be seen in the column 4 of Table 5.2.

\subsubsection{Probabilistic estimation}

In this section, we are going to sample data survey for each survey, using the joint trinomial distribution set in Table 5.2. This will be done a high number 


\begin{tabular}{|c|c|c|c|}
\hline & $\begin{array}{c}\text { Survey } \\
\text { dates }\end{array}$ & $\begin{array}{c}\text { Sample } \\
\text { size }\end{array}$ & Joint trinomial probability function \\
\hline$j=1$ & $t_{1}=$ May 05 & $n_{1}=1800$ & $P_{1800}^{1}\left(x_{1}, x_{2}, x_{3}\right)=\frac{1800 !}{x_{1} ! x_{2} ! x_{3} !} 0.02^{x_{1}} 0.93^{x_{2}} 0.05^{x_{3}}$ \\
\hline$j=2$ & $t_{2}=$ Nov 05 & $n_{2}=1200$ & $P_{1200}^{2}\left(x_{1}, x_{2}, x_{3}\right)=\frac{1200 !}{x_{1} ! x_{2} ! x_{3} !} 0.03^{x_{1}} 0.93^{x_{2}} 0.04^{x_{3}}$ \\
\hline$j=3$ & $t_{3}=$ May 06 & $n_{3}=1800$ & $P_{1800}^{3}\left(x_{1}, x_{2}, x_{3}\right)=\frac{1800 !}{x_{1} ! x_{2} ! x_{3} !} 0.03^{x_{1}} 0.93^{x_{2}} 0.04^{x_{3}}$ \\
\hline$j=4$ & $t_{4}=$ Nov 06 & $n_{4}=1200$ & $P_{1200}^{4}\left(x_{1}, x_{2}, x_{3}\right)=\frac{1200 !}{x_{1} ! x_{2} ! x_{3} !} 0.04^{x_{1}} 0.86^{x_{2}} 0.1^{x_{3}}$ \\
\hline$j=5$ & $t_{5}=$ May 07 & $n_{5}=1200$ & $P_{1200}^{5}\left(x_{1}, x_{2}, x_{3}\right)=\frac{1200 !}{x_{1} ! x_{2} ! x_{3} !} 0.02^{x_{1}} 0.84^{x_{2}} 0.14^{x_{3}}$ \\
\hline$j=6$ & $t_{6}=\operatorname{Nov} 07$ & $n_{6}=1200$ & $P_{1200}^{6}\left(x_{1}, x_{2}, x_{3}\right)=\frac{1200 !}{x_{1} ! x_{2} ! x_{3} !} 0.02^{x_{1}} 0.9^{x_{2}} 0.08^{x_{3}}$ \\
\hline$j=7$ & $t_{7}=$ May 08 & $n_{7}=1800$ & $P_{1800}^{7}\left(x_{1}, x_{2}, x_{3}\right)=\frac{1800 !}{x_{1} ! x_{2} ! x_{3} !} 0.03^{x_{1}} 0.9^{x_{2}} 0.07^{x_{3}}$ \\
\hline$j=8$ & $t_{8}=$ Nov 08 & $n_{8}=1200$ & $P_{1200}^{8}\left(x_{1}, x_{2}, x_{3}\right)=\frac{1200 !}{x_{1} ! x_{2} ! x_{3} !} 0.01^{x_{1}} 0.93^{x_{2}} 0.06^{x_{3}}$ \\
\hline$j=9$ & $t_{9}=$ May 09 & $n_{9}=1200$ & $P_{1200}^{9}\left(x_{1}, x_{2}, x_{3}\right)=\frac{1200 !}{x_{1} ! x_{2} ! x_{3} !} 0.04^{x_{1}} 0.9^{x_{2}} 0.06^{x_{3}}$ \\
\hline$j=10$ & $t_{10}=$ Nov 09 & $n_{10}=1200$ & $P_{1200}^{10}\left(x_{1}, x_{2}, x_{3}\right)=\frac{1200 !}{x_{1} ! x_{2} ! x_{3} !} 0.03^{x_{1}} 0.89^{x_{2}} 0.08^{x_{3}}$ \\
\hline$j=11$ & $t_{11}=$ May 10 & $n_{11}=1200$ & $P_{1200}^{11}\left(x_{1}, x_{2}, x_{3}\right)=\frac{1200 !}{x_{1} ! x_{2} ! x_{3} !} 0.03^{x_{1}} 0.9^{x_{2}} 0.07^{x_{3}}$ \\
\hline$j=12$ & $t_{12}=$ Nov 10 & $n_{12}=1200$ & $P_{1200}^{12}\left(x_{1}, x_{2}, x_{3}\right)=\frac{1200 !}{x_{1} ! x_{2} ! x_{3} !} 0.04^{x_{1}} 0.88^{x_{2}} 0.08^{x_{3}}$ \\
\hline$j=13$ & $t_{13}=$ May 11 & $n_{13}=1200$ & $P_{1200}^{13}\left(x_{1}, x_{2}, x_{3}\right)=\frac{1200 !}{x_{1} ! x_{2} ! x_{3} !} 0.04^{x_{1}} 0.9^{x_{2}} 0.06^{x_{3}}$ \\
\hline$j=14$ & $t_{14}=$ Nov 11 & $n_{14}=1200$ & $P_{1200}^{14}\left(x_{1}, x_{2}, x_{3}\right)=\frac{1200 !}{x_{1} ! x_{2} ! x_{3} !} 0.03^{x_{1}} 0.89^{x_{2}} 0.08^{x_{3}}$ \\
\hline$j=15$ & $t_{15}=$ May 12 & $n_{15}=1200$ & $P_{1200}^{15}\left(x_{1}, x_{2}, x_{3}\right)=\frac{1200 !}{x_{1} ! x_{2} ! x_{3} !} 0.05^{x_{1}} 0.89^{x_{2}} 0.06^{x_{3}}$ \\
\hline$j=16$ & $t_{16}=\operatorname{Nov} 12$ & $n_{16}=1200$ & $P_{1200}^{16}\left(x_{1}, x_{2}, x_{3}\right)=\frac{1200 !^{3}}{x_{1} ! x_{2} ! x_{3} !} 0.03^{x_{1}} 0.92^{x_{2}} 0.05^{x_{3}}$ \\
\hline
\end{tabular}

Table 5.2: Data for probabilistic model estimation. Date, sample size and joint trinomial probability function of each survey. Using these distributions we will be able to compute their $95 \%$ confidence intervals. Also, the model will be fitted with samples of these probability distributions.

of times $\left(10^{4}\right.$ times $)$ in order to generate a representative sample for each survey. Every time we sample data survey, we determine the model parameter estimations $\gamma_{12}, \gamma_{13}, \gamma_{23}$, using the Nelder-Mead optimization algorithm [49, $55]$ with goodness-of-fit $\chi^{2}$-test [24]. The parameters with $p$-value less than 0.05 will be rejected. The remainder will be sorted by $p$-value descending order. Selecting some of these model parameter vectors, we will be able to use the model outputs to provide a confidence band determined by the percentiles 2.5 and 97.5 (95\% confidence interval) in each time instant. This $95 \%$ model confidence band $(95 \% \mathrm{MCB})$ is what we call probabilistic estimation. Let us describe in detail the procedure.

1. Compute the quantiles 2.5 and 97.5 (95\% CI) of each one of the joint multinomial distributions in Table $5.2, j=1,2, \ldots, 16$, for Support, Rejection and Abstention subpopulations, obtaining 


$$
\begin{aligned}
Q_{2.5}^{\text {support }}= & (1.39,2.08,2.22,2.92,1.25,1.25,2.22,0.50,2.92, \\
& 2.08,2.08,2.92,2.92,2.08,3.83,2.08), \\
Q_{97.5}^{\text {support }}= & (2.67,4.00,3.78,5.17,2.83,2.83,3.83,1.58,5.17, \\
& 4.00,4.00,5.17,5.17,4.00,6.25,4.00), \\
Q_{2.5}^{\text {reject }}= & (91.80,91.50,91.80,84.00,81.90,88.20,88.60,91.50, \\
& 88.20,87.20,88.20,86.20,88.20,87.20,87.20,90.40), \\
Q_{97.5}^{\text {reject }}= & (94.20,94.40,94.20,87.90,86.10,91.70,91.40,94.40, \\
& 91.70,90.70,91.70,89.80,91.70,90.70,90.70,93.50), \\
Q_{2.5}^{\text {abstention }}= & (4.00,2.92,3.11,8.33,12.10,6.50,5.83,4.67,4.67, \\
& 6.50,5.58,6.50,4.67,6.50,4.67,3.83), \\
Q_{97.5}^{\text {abstention }}= & (6.00,5.17,4.94,11.80,16.00,9.58,8.22,7.33,7.33, \\
& 9.58,8.50,9.58,7.33,9.58,7.42,6.25) .
\end{aligned}
$$

The 95\% CI determined by the above percentiles (they can be seen in Figures 5.2 and 5.3 as vertical segments (error bars)) constitute an approximation of the survey results. Moreover, these 95\% CI will be valuable to find the best probabilistic estimation.

2. Let us define the following function of the parameters $\gamma_{12}, \gamma_{13}$ and $\gamma_{23}$ :

A) For given values of $\gamma_{12}, \gamma_{13}$ and $\gamma_{23}$ parameters, compute the model output in $t_{1}=$ May $2005, t_{2}=$ Nov $2005, \ldots, t_{15}=$ May 2012 and $t_{16}=$ Nov 2012 for the three subpopulations, Support, Rejection and Abstention.

B) Compare, for each subpopulation, the model output obtained in step (2A) to the data values we will sample in step (3A) using the $\chi^{2}$-test and obtain a $p$-value for each subpopulation.

C) Calculate the minimum $p$-value among the three above.

3. For $i=1$ to $10^{4}$

A) Sample values of all the trinomial distributions in Table 5.2. Then, we will have one sample of 16 surveys with percentages for Support, Rejection and Abstention populations from May 2005 until Nov 2012. Therefore, we will have a set of sampled data as in Table 5.1. 
B) Find the model parameter values $\gamma_{12}^{i}, \gamma_{13}^{i}$ and $\gamma_{23}^{i}$ with the highest $p$-value (maximizing the function defined in steps $(2 \mathrm{~A}),(2 \mathrm{~B})$ and $(2 \mathrm{C})$ ). To do that, Nelder-Mead optmization algorithm is used $[49,55]$ using as a goodness-of-fit the $\chi^{2}$-test.

4. Once the above process is completed, store the obtained parameter values and the $p$-value as the vector

$$
\left(\gamma_{12}^{i}, \gamma_{13}^{i}, \gamma_{23}^{i}, p-\text { value }_{i}\right), 1 \leq i \leq 10^{4}
$$

5. Reject the model parameters with $p$-value less than 0.05 . In our case, 4990 out of $10^{4}$ satisfy this restriction. Then, they are sorted by $p$-value descending order as follows,

$$
\left(\gamma_{12}^{i}, \gamma_{13}^{i}, \gamma_{23}^{i}, p-\text { value }_{i}\right), 1 \leq i \leq 4990 .
$$

6. For $k=2$ to 4990

A) Substitute into the model the parameters $\left(\gamma_{12}^{j}, \gamma_{13}^{j}, \gamma_{23}^{j}\right)$, for $j=$ $1,2, \ldots, k$, and compute the model output in $t_{1}=$ May 2005, $t_{2}=$ Nov $2005, \ldots, t_{15}=$ May 2012 and $t_{16}=$ Nov 2012 .

a1) Take the $k$ model outputs for Support, Rejection and Abstention at time instant $t_{1}=$ May 2005 and calculate the corresponding quantiles 2.5 and 97.5 (95\% CI).

a2) Take the $k$ model outputs for Support, Rejection and Abstention at time instant $t_{2}=$ Nov 2005 and calculate the corresponding quantiles 2.5 and 97.5 (95\% CI).

$-\cdots$

a16) Take the $k$ model outputs for Support, Rejection and Abstention at time instant $t_{16}=$ Nov 2012 and calculate the corresponding quantiles 2.5 and 97.5 (95\% CI).

B) Now, gather the 16 calculated quantiles 2.5 for Support, Rejection and Abstention subpopulations and store them sequentially on the vectors $S_{2.5}^{k}, R_{2.5}^{k}$ and $A_{2.5}^{k}$, respectively.

C) Gather the 16 calculated quantiles 97.5 for Support, Rejection and Abstention subpopulations and store them sequentially on the vectors $S_{97.5}^{k}, R_{97.5}^{k}$ and $A_{97.5}^{k}$, respectively.

D) Calculate the $p$-values using the $\chi^{2}$-test to datasets obtained in steps (1), (6B) and (6C) grouped in pairs as follows, 

d1) $Q_{2.5}^{\text {support }}$ and $S_{2.5}^{k}$,
d2) $Q_{97.5}^{\text {support }}$ and $S_{97.5}^{k}$,
d3) $Q_{2.5}^{\text {reject }}$ and $R_{2.5}^{k}$,
d4) $Q_{97.5}^{\text {reject }}$ and $R_{97.5}^{k}$
d5) $Q_{2.5}^{\text {abstention }}$ and $A_{2.5}^{k}$,
d6) $Q_{97.5}^{\text {abstention }}$ and $A_{97.5}^{k}$.

Note that, in order to know the parameter values which allow us to define the $95 \%$ MCB (probabilistic estimation), we compare percentil vectors obtained by the trinomial sampling to the obtained using the model outputs considering the 4990 optimal values.

E) Calculate $m_{k}$ the minimum $p$-value among the six above and build the pair $\left(k, m_{k}\right)$.

7. Select the pair $\left(k, m_{k}\right)$ among the 4990 with the maximum $m_{k}$.

In our case, the obtained value is $k=77$ with $m_{77}=0.972991$ and consequently the $p$-values corresponding to percentiles 2.5 and 97.5 for each subpopulation are greater than $m_{77}$.

Now, we take the $k=77$ set of parameters obtained in the above procedure, compute the model output from $t_{1}=$ May 2005 to $t_{16}=$ Nov 2012, in jumps of 0.05 and, in each point, we calculate the percentiles 2.5 and 97.5 for each subpopulation (95\% MCB). The result (probabilistic estimation) is depicted in Figure 5.2 as red continuous lines.

The vertical segments (error bars) correspond to the $95 \%$ CI of the survey data simulated by multinomial distributions appearing in Table 5.2. The points in the middle of the segments are the mean values collected in Table 5.1. The continuous lines are the model 95\% MCB obtained from the model outputs of the first $k=77$ out of 4990 sets of model parameters that best fit samples of the multinomial distributions in Table 5.2.

\subsubsection{Probabilistic estimation analysis}

The idea of the probabilistic estimation described in the previous section is to obtain $95 \%$ model confidence interval bands (MCB) as close as possible, in the sense of $\chi^{2}$-test, to $95 \%$ CI of the data distributions appearing in Table 5.2 (vertical segments in Figure 5.2). This closeness depends on the model and on the data.

Looking at the graphics in Figure 5.2, we can see that almost all the vertical segments (error bars) cross at least a continuous line indicating that 

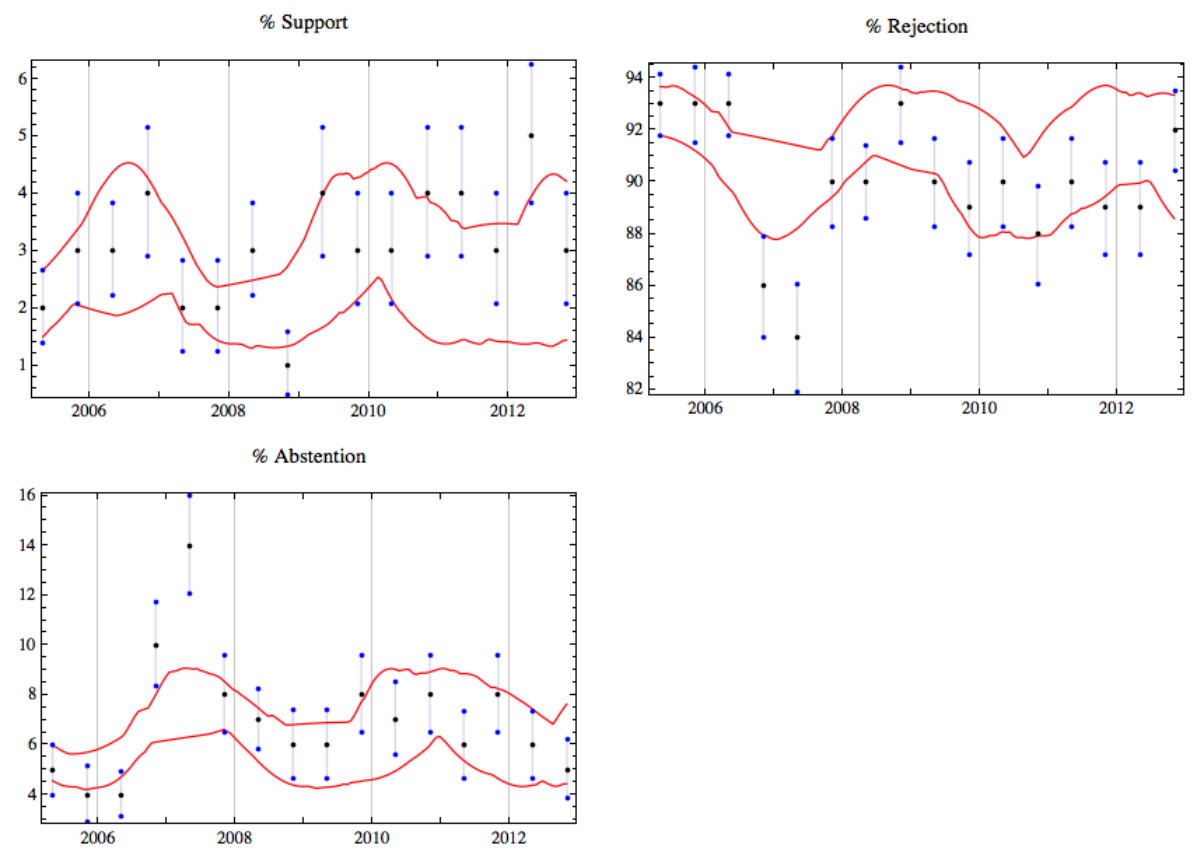

Figure 5.2: Probabilistic estimation. The vertical segments (error bars) correspond to the $95 \% \mathrm{CI}$ of the simulated data using multinomial distributions appearing in Table 5.2. The points in the middle of the segments are the mean values in Table 5.1. The continuous lines are the model 95\% MCB (probabilistic estimation) obtained with the described procedure. Note that most of the segments cross continuous lines determined by the model, capturing the data uncertainty. Only for Rejection and Abstention subpopulations in time instants Nov 2006 and May 2007 the uncertainty is not captured.

data uncertainty is captured by the model, in particular for Support subpopulation.

Nevertheless, in Social Sciences the data may be very sensitive to punctual events and these events hardly are captured by the model. This happens if we study the Rejection and Abstention subpopulation graphics, where we can distinguish two parts. The first one, from May 2005 to May 2007, the probabilistic estimation intends to follow the data trajectory but the data uncertainty in Nov 2006 and May 2007 is not captured when sudden jumps appear. As we mentioned in Chapter 2 and can also be seen in Figures 2.1, 2.2 and 2.3, large jumps in the Rejection population correspond to large jumps in the Abstention population, in the opposite direction. We consider that the jumps in Nov 2006 and May 2007 are due to certain events that occurred from Sep 2006 to May 2007 as: increasing of vandalism acts from 
Sep 2006 to Dec 2006 linked with young left-wing nationalist groups; Barajas Airport Terminal 4 attack claimed by ETA (Dec 2006); in May 2007 local elections, the left-wing nationalist party EAE-ANV was allowed to present candidates in some villages and cities. In the second part, from Nov 2007 until Nov 2012, the continuous lines capture the data uncertainty.

Therefore, even though the estimation for Rejection and Abstention subpopulations do not capture the data uncertainty in two time instants, the three subpopulations capture the remainder and this leads us to consider the model and its probabilistic estimation appropriate to provide a prediction of the evolution of the population's attitude towards ETA over the next four years.

\subsection{Probabilistic predictions over the next four years}

Now, taking the model and the $k=77$ set of parameters obtained in the probabilistic estimation, we are going to give the probabilistic prediction over the next four years by computing the model outputs from Nov 2012 to Nov 2016 and then, obtaining the 95\% MCB (model continuous lines). We plot the results graphically in Figure 5.3 and some numerical values in Table 5.3 .

\begin{tabular}{|c|c|c|c|c|c|c|}
\hline Date & \multicolumn{2}{|c|}{ Support } & \multicolumn{2}{c|}{ Rejection } & \multicolumn{2}{c|}{ Abstention } \\
& Mean & 95\% CI & Mean & $95 \%$ CI & Mean & $95 \%$ CI \\
\hline May 2013 & 3.10 & {$[1.54,4.32]$} & 90.69 & {$[88.02,93.38]$} & 6.22 & {$[4.52,9.01]$} \\
Nov 2013 & 2.98 & {$[1.55,4.54]$} & 90.28 & {$[88.11,93.15]$} & 6.74 & {$[4.63,8.87]$} \\
May 2014 & 2.68 & {$[1.41,4.06]$} & 90.40 & {$[87.87,92.90]$} & 6.92 & {$[4.63,8.78]$} \\
Nov 2014 & 2.43 & {$[1.43,3.88]$} & 90.86 & {$[88.21,93.55]$} & 6.71 & {$[4.74,8.90]$} \\
May 2015 & 2.44 & {$[1.47,3.84]$} & 91.23 & {$[89.03,93.41]$} & 6.34 & {$[4.33,8.66]$} \\
Nov 2015 & 2.62 & {$[1.42,4.26]$} & 91.22 & {$[88.76,93.25]$} & 6.17 & {$[4.60,8.08]$} \\
May 2016 & 2.72 & {$[1.42,4.17]$} & 91.01 & {$[88.56,93.39]$} & 6.27 & {$[4.49,8.99]$} \\
Nov 2016 & 2.72 & {$[1.46,4.28]$} & 90.87 & {$[88.13,93.13]$} & 6.41 & {$[4.43,8.82]$} \\
\hline
\end{tabular}

Table 5.3: Mean and 95\% confidence interval predictions for the coming eight Euskobarometro surveys.

Figure 5.3 and Table 5.3 show us that the attitude towards ETA of the population living in the Basque Country will remain fairly stable over the next four years. 

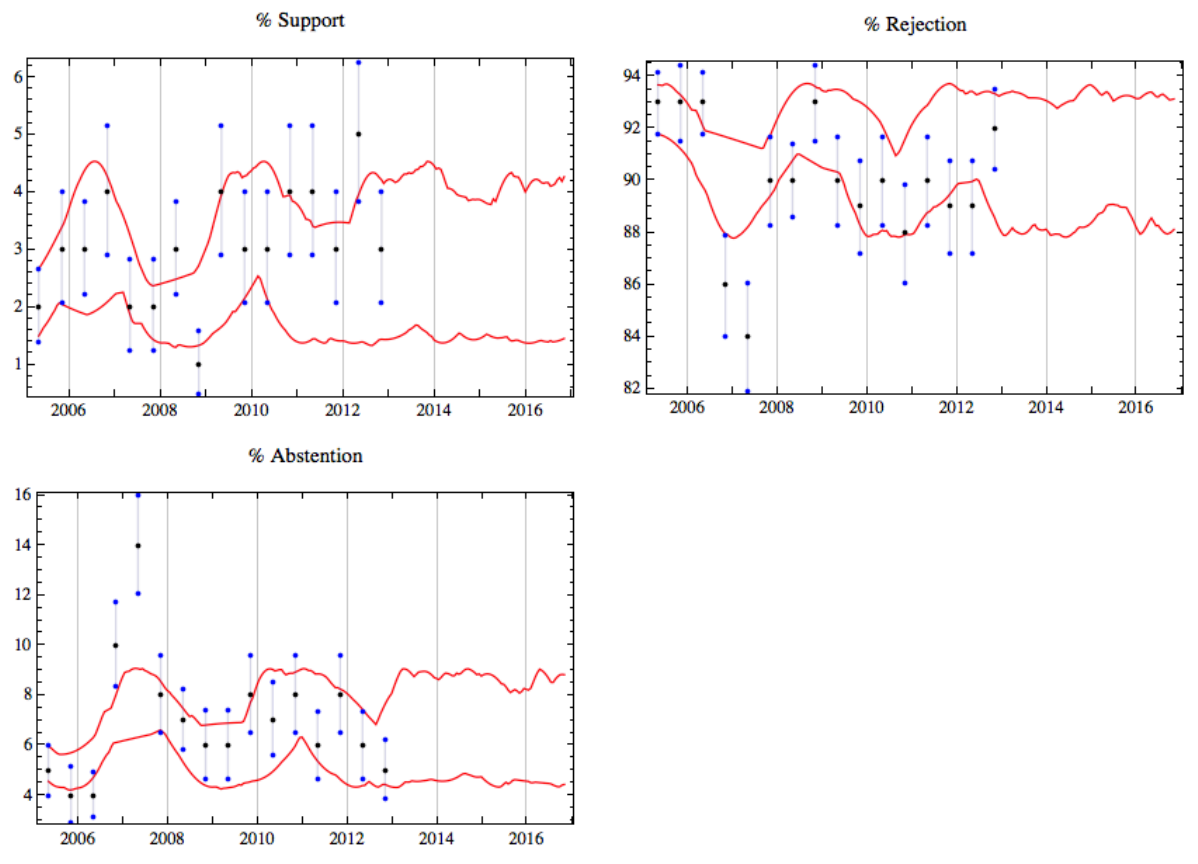

Figure 5.3: Probabilistic prediction. This picture is the Figure 5.2 including the predictions over the next four years as $95 \%$ MCB (model continuous lines).

\subsubsection{Robustness of the presented method}

Note that if we run the described procedure again, taking into account that the multinomial sampling is random, we may obtain a different value of $k$, however, the corresponding $m_{k}$ will be very similar. In fact, we did it two more times obtaining $k=129$ and $k=84$ with $m_{k}=0.9624$ and $m_{k}=0.966348$, respectively. The probabilistic estimations in these two new cases are given in Tables 5.4 and 5.5. We can see that the predictions were very similar. This shows the robustness of the proposed method.

Also, we should say that last June 27th, 2013 was published the Euskobarometro of May 2013 with 1200 interviews and values given in Table 5.6. The $95 \%$ confidence intervals of this last Euskobarometro were calculated as in the Step 1 of the procedure described in Section 5.2.2.

Comparing data in Table 5.6 to results in Tables 5.3, 5.4 and 5.5, we can see that the data uncertainty in Euskobarometro May 2013 is captured by our predictions in the three tables. 


\begin{tabular}{|c|c|c|c|c|c|c|}
\hline Date & \multicolumn{2}{|c|}{ Support } & \multicolumn{2}{c|}{ Rejection } & \multicolumn{2}{c|}{ Abstention } \\
& Mean & $95 \%$ CI & Mean & $95 \%$ CI & Mean & $95 \%$ CI \\
\hline May 2013 & 3.08 & {$[1.48,4.76]$} & 91.02 & {$[88.40,93.44]$} & 5.90 & {$[4.42,8.33]$} \\
Nov 2013 & 3.09 & {$[1.59,4.61]$} & 90.41 & {$[87.90,93.33]$} & 6.50 & {$[4.35,8.97]$} \\
May 2014 & 2.86 & {$[1.39,4.52]$} & 90.30 & {$[88.05,92.89]$} & 6.84 & {$[4.43,8.89]$} \\
Nov 2014 & 2.59 & {$[1.48,4.22]$} & 90.64 & {$[88.50,93.28]$} & 6.77 & {$[4.15,8.71]$} \\
May 2015 & 2.45 & {$[1.46,3.86]$} & 91.10 & {$[88.54,93.21]$} & 6.45 & {$[3.89,8.53]$} \\
Nov 2015 & 2.51 & {$[1.56,3.93]$} & 91.35 & {$[88.98,93.31]$} & 6.14 & {$[3.67,8.41]$} \\
May 2016 & 2.67 & {$[1.47,4.32]$} & 91.28 & {$[88.79,93.33]$} & 6.05 & {$[3.56,8.29]$} \\
Nov 2016 & 2.75 & {$[1.31,4.40]$} & 91.06 & {$[88.09,93.19]$} & 6.19 & {$[3.74,8.75]$} \\
\hline
\end{tabular}

Table 5.4: Mean and 95\% confidence interval predictions for the coming eight Euskobarometro surveys for the second procedure execution, $k=129$ and $m_{k}=0.9624$.

\begin{tabular}{|c|c|c|c|c|c|c|}
\hline Date & \multicolumn{2}{|c|}{ Support } & \multicolumn{2}{c|}{ Rejection } & \multicolumn{2}{c|}{ Abstention } \\
& Mean & 95\% CI & Mean & $95 \%$ CI & Mean & $95 \%$ CI \\
\hline May 2013 & 3.13 & {$[1.73,4.79]$} & 90.89 & {$[88.29,93.22]$} & 5.98 & {$[4.47,8.32]$} \\
Nov 2013 & 3.08 & {$[1.79,4.59]$} & 90.34 & {$[87.87,92.99]$} & 6.57 & {$[4.38,8.81]$} \\
May 2014 & 2.85 & {$[1.47,4.61]$} & 90.31 & {$[88.17,92.28]$} & 6.84 & {$[4.79,8.89]$} \\
Nov 2014 & 2.56 & {$[1.47,4.23]$} & 90.66 & {$[88.11,92.88]$} & 6.78 & {$[4.79,8.67]$} \\
May 2015 & 2.39 & {$[1.50,3.66]$} & 91.12 & {$[88.65,93.34]$} & 6.50 & {$[4.27,8.51]$} \\
Nov 2015 & 2.48 & {$[1.54,3.84]$} & 91.34 & {$[89.30,93.05]$} & 6.18 & {$[4.40,8.37]$} \\
May 2016 & 2.67 & {$[1.47,4.26]$} & 91.17 & {$[88.63,93.08]$} & 6.15 & {$[4.71,8.09]$} \\
Nov 2016 & 2.71 & {$[1.43,4.35]$} & 90.94 & {$[87.93,93.28]$} & 6.35 & {$[4.18,8.69]$} \\
\hline
\end{tabular}

Table 5.5: Mean and 95\% confidence interval predictions for the coming eight Euskobarometro surveys for the third procedure execution, $k=84$ and $m_{k}=0.966348$.

\subsection{Conclusion}

In this chapter, it is presented a computational technique to deal with uncertainty (in parameter estimation and output predictions) in dynamic social models based on systems of differential equations. This technique takes data from surveys to introduce the uncertainty into the model from the very beginning and returns $95 \%$ model confidence interval bands that capture the data uncertainty and predict what will happen in the near future.

The technique is applied to study the evolution dynamics of the attitude of Basque population towards ETA using the model stated in Chapter 4. Thus, we determine a probabilistic estimation in order to find out if the model captures the Euskobarometro data evolution. We observe that the model captures the data uncertainty only partially from May 2005 to May 2007, but 


\begin{tabular}{|c|c|c|c|c|c|c|}
\hline Date & \multicolumn{2}{|c|}{ Support } & \multicolumn{2}{c|}{ Rejection } & \multicolumn{2}{c|}{ Abstention } \\
& Mean & 95\% CI & Mean & 95\% CI & Mean & 95\% CI \\
\hline May 2013 & 3 & {$[2.08,4.00]$} & 89 & {$[87.17,90.75]$} & 8 & {$[6.50,9.58]$} \\
\hline
\end{tabular}

Table 5.6: Mean and 95\% confidence interval of the Euskobarometro corresponding to May 2013.

from Nov 2007 the probabilistic estimation improves perceptibly. Anyway, the model estimation is non-rejectable using the $\chi^{2}$-test. Then, we provide a probabilistic prediction of the attitude towards ETA of the population of the Basque Country over the next four years. Prediction figures indicate stabilization in the evolution of the attitudes towards ETA over the next few years, and therefore stabilization in a hypothetical pool of candidates willing to join the organization in upcoming years. As a result, the presented prediction states that the popular support to the ETA will remain stable, if and when the current scenario does not change.

Additionally, some benefits that can be obtained with this approach are:

- If we consider the model parameters as random variables, the technique presented here as probabilistic estimation allows the estimation of samples of these model parameters (Steps 3, 4 and 5 of the procedure described in Section 5.2.2). This fact is of paramount interest because one of main challenges in modelling real problems using random differential equations is to determine the distribution function of model parameters. Therefore, if we use the probabilistic estimation to obtain some samples of the model parameters, in our case $k=77$ parameter samples, we can use these samples and statistical hypothesis testing or kernel functions in order to find distribution functions of the model parameters.

- Other aspect that should be mentioned and it could be interesting for survey prediction estimations is the fact that Table 5.3 (5.4 and 5.5) may be considered as an estimation of the results of the coming Euskobarometro surveys (mean and 95\% confidence interval). This idea may be applied to this and other type of surveys where a reliable underlying dynamic model can be built. As a consequence, some surveys may not be carried out with the corresponding saving of money. Therefore, we consider that this approach may be an interesting tool for social behavior studies. 


\section{Chapter 6}

\section{Conclusion}

In this dissertation, we focus our study in the especial situation occurring in the Basque Country where the Basque revolutionary organisation ETA has been using different forms of terrorism to achieve its political goals. Popular support is an important enabler for radical violent organizations and it may be crucial for their survival. At the same time, extremist groups have also an impact in the societies where they are inserted, especially if those groups are engaged in violent activities. Social and behavioral scientists try to find clues about how that interaction may affect those people, either at the group or at the individual level, in order to foresee subsequent dynamics.

To do that, we propose mathematical models to analyse the dynamics of the attitude the Basque Country population have towards ETA, its goals and the means it uses to achieve them. These models allow us to know if there will be a reduction in the population of ETA's supporters, the main source of ETA members, or not. Taking into account the unpredictability of the human behavior, errors in data, etc., it is necessary to introduce the treatment of the uncertainty in the proposed models. Modelling and treatment of the uncertainty are the main threads across the chapters of the present dissertation, on the one hand stating a reliable and well supported model and, on the other hand, using known techniques to deal with uncertainty and proposing new ones.

As a result of the work done with the above goals in mind, in the following, we point out the main general conclusions of this dissertation:

1. Under the Socio-Political point of view:

- The "Law of Political Parties" produced, from May 2002 to May 2005, an increase of $2.59 \%$ in the lower case and an increase of $13.38 \%$ in the higher case of the people with a rejection attitude towards ETA. Therefore, even though there are important political 
parties, mass media and organizations supporting the negotiation with ETA as the best choice to finish with its activities, the appropriate use of the laws is an useful tool to fight against these extreme organizations and change the citizen's mind against their social pressure.

- Prediction figures indicate stabilization in the evolution of the attitudes towards ETA over the next few years, and therefore stabilization in a hypothetical pool of candidates willing to join the organization in upcoming years. As a result, the presented prediction states that the popular support to the ETA will remain stable, if and when the current scenario does not change, and around $3 \%$ (with a minimum of $1.41 \%$ and a maximum of $4.54 \%$ ) of the Basque citizens will support ETA unconditionally over the next four years.

2. Under the Mathematical point of view:

- We have helped to introduce dynamic mathematical models in a complex area of Social Sciences as is the ideological or opinion dynamic evolution.

- The introduction of these dynamical models has been carried out using real data with short and medium term forecasting, not via the classical approaches using dynamic analysis techniques.

- The relation with the expert has been crucial in this dissertation development to address properly this research. This relation provided the possibility of developing interesting research worthy in both areas, Social Sciences and Mathematics.

- We have provided a useful example of dynamic models based on differential equations to quantify, a posteriori, the effect of government laws.

- We have provided some advances in the introduction of uncertainty in dynamic models. To be precise, in Chapter 5 we have proposed a computational technique to deal with the uncertainty from the very beginning facing relevant problems as the knowledge of the probability distribution of the parameters and initial conditions and saving computational issues appearing when we tackle realistic models with a high number of equations and parameters.

As a final conclusion, we would like to say that, under our point of view, uncertainty treatment should be considered as an important part of the model building and analysis. 


\section{Bibliography}

[1] A. Abadie, J. Gardeazabal, The economic costs of conflict: A casecontrol study for the Basque Country, American Economic Review 93 (1) 113-132 (2003).

[2] J.A. Adam, J.A. Sokolowski, C.M. Banks, A two-population insurgency in Colombia: Quasi-predator-prey models-A trend towards simplicity, Mathematical and Computer Modelling 49 (5-6) 1115 - 1126 (2009), doi: 10.1016/j.mcm.2008.03.017.

[3] J. Alcaide, Evolución de la población española en el siglo XX, por provincias y comunidades autónomas (Evolution of the Spanish population in the 20th century, by provinces anc autonomous communities), Fundación BBVA, 2007.

[4] R. Alonso, F. Reinares, Terrorism, human rights and law enforcement in Spain, In: Ranstorp, M. and Wilkison, P. (Eds.), Terrorism and human rights (2008).

[5] C. Arney, Mathematical Modeling of "hearts and minds" in the Terrorism/Counter-Terrorism Struggle, http:// jointmathematicsmeetings . org/meetings/national/jmm/1067r1-237.pdf (2010).

[6] Auto del Juzgado Central de Instrucción n. 5, Madrid, de 26 de agosto de 2002. Sumario 25/02 Y (Central Court Order No. 5, August 25th 2002, Summary 25/02 Y).

[7] V.A. Bali, Terror and elections: Lessons from Spain, Electoral Studies 26 (3) 669 - 687 (2007), doi: 10.1016/j.electstud.2007.04.004.

[8] H.T. Banks, C. Castillo-Chávez (Editors), Bioterrorism: Mathematical Modeling Applications in Homeland Security, in: SIAM Frontiers in Applied Mathematics, vol. 28, SIAM, Philadelphia (2003). 
[9] C.P. Barros, An intervention analysis of terrorism: The Spanish ETA case, Defence and Peace Economics 14 (6) 401-412 (2003).

[10] C.P. Barros, L.A., Gil-Alana, ETA: A persistence phenomenon, Defence and Peace Economics 17 (2) 95-116 (2006).

[11] C.P. Barros, J.P. Passos, L.A. Gil-Alana, The timing of ETA terrorist attacks, Journal of Policy Modeling 28 (3) 335 - 346 (2006), doi: 10.1016/j.jpolmod.2005.12.001.

[12] L.M.A. Bettencourt, A. Cintrón-Arias, D.I. Kaiser, C. Castillo-Chávez, The power of a good idea: Quantitative modeling of the spread of ideas from epidemiological models, Physica A: Statistical Mechanics and its Applications 364513 - 536 (2006), 10.1016/j.physa.2005.08.083.

[13] A. de Blas, J. Pastor (Eds.), Fundamentos de ciencia política (Basics on political sciences), UNED (2001).

[14] S.M. Blower, H. Dowlatabadi, Sensitivity and Uncertainty Analysis of Complex Models of Disease Transmission: and HIV Model, as an Example, International Statistical Review 62 (2) 229-243 (1994).

[15] Boletín Oficial de la Cortes Generales (Diary of the Spanish Parliament). Available at http://www.congreso.es/public_oficiales/L8/CONG/ BOCG/D/D_204.PDF.

[16] M. Buesa, ETA S.A. El dinero que mueve el terrorismo y los costes que genera (ETA Inc. The money moved by terrorism and the generated cost), Ed. Planeta (2011).

[17] C. Castillo-Chávez, B. Song, Models for the transmission dynamics of fanatic behavior, in: H.T. Banks, C. Castillo-Chávez (Eds.), Bioterrorism: Mathematical Modeling Applications in Homeland Security, in: SIAM Frontiers in Applied Mathematics, vol. 28, SIAM, Philadelphia, pp. $155-172$ (2003).

[18] B.M. Chen-Charpentier, J.C. Cortes, J.V. Romero, M.D. Rosello, Some recommendations for applying gPC (generalized polynomial chaos) to modeling: An analysis through the Airy random differential equation, Appl. Math. Comput. 219, 4208-4218 (2013), doi: 10.1016/j.amc.2012.11.007.

[19] A. Cherif, H. Yoshioka, W. Ni, P. Bose, Terrorism: Mechanism of Radicalization Process, Control of Contagion and Counter-Terrorist Measures, http://arxiv.org/pdf/0910.5272.pdf (2010). 
[20] F.C. Coelho, C.T. Codeço, M.G.M. Gomes, A bayesian framework for parameter estimation in dynamical models, PLoS ONE 6(5):e19616 (2011), doi: 10.1371/journal.pone0019616.

[21] Communiqué of ETA January 8th 2011. Video published in GARA. Available at http://www.gara.net/bideoak/110108_video/ (in Spanish).

[22] J.C. Cortes, M. Ehrhardt, A. Sanchez-Sanchez, F.J. Santonja, R.J. Villanueva, Modelling the dynamics of the students academic performance in the German region of North Rhine-Westphalia: an epidemiological approach with uncertainty, International Journal of Computer Mathematics (in press) (2013), doi: 10.1080/00207160.2013.813937.

[23] N.A. Christakis, J.H., Fowler, Connected: the surprising power of our social networks and how they shape our lives. Brown and Company. Hachette Book Group. (2009).

[24] M.H. DeGroot, Probability and Statistics, Addison-Wesley, New York, 1986.

[25] J.M. de Pablo, La cuarta trama. Verdades y mentiras en el caso del 11-M (The 4th conspiracy. Trues and lies about 11-M), Ed. Ciudadela, (2009).

[26] Diáspora democrática vasca (Basque democratic diaspora), Cuadernos de Ermua http://www.foroermua.com/CuadernosdeErmua17.pdf (in Spanish)

[27] G. Dogan, Bootstrapping for confidence interval estimation and hypothesis for parameters of system dynamics models, System Dynamics Review 23 (2007) 415-436.

[28] F. Dominguez, Dentro de ETA (Inside ETA), Ed. Punto de lectura (2006).

[29] El libro negro de ETA (The black book of ETA) http: //www.libertaddigital.com/opinion/mikel-buesa/el-libronegro-de-eta-68926/ (in Spanish)

[30] W. Enders, T. Sandler, Causality between transnational terrorism and tourism: The case of Spain, Terrorism 14 (1) 49-58 (1991).

[31] W. Enders, T. Sandler, Terrorism and foreign direct investment in Spain and Greece, Kyklos 49 (3) 331-352 (1996). 
[32] ETA's delaration of cease-fire, Jan 8th, 2011 http://www. elpais.com/elpaismedia/ultimahora/media/201101/10/espana/ 20110110elpepunac_1_Pes_PDF.pdf (in Spanish)

[33] Euskobarometro data series. Available at http://www.ehu.es/ euskobarometro/.

[34] Euskobarometro report, http://www.ehu.es/euskobarometro/index. php?option=com_content\&view=article\&id=152\&Itemid $=52$

[35] P.F. Fournier, R. Nadeau, A. Blais, E. Gidengil, N. Nevitte, Time-ofvoting decision and susceptibility to campaign effects, Electoral Studies 23 (4) 661 - 681 (2004), doi: 10.1016/j.electstud.2003.09.001.

[36] R. Ghanem, P. Spanos, Stochastic Finite Elements: A Spectral Approach, Dover Publications, New York, (2003).

[37] F. Guerrero, F.J. Santonja, R.J. Villanueva, Analysing the Spanish smoke-free legislation of 2006: a new method to quantify its impact using a dynamic model, International Journal of Drug Policy 22-4 (2011) 247-251.

[38] J.F. Hair, R.E. Anderson, R.L. Tatham, W.C. Black, Multivariate Data Analysis, Prentice-Hall, 2006.

[39] C.C. Harmon, Spain's ETA Terrorist Group is Dying, Orbis, Volume 56, Issue 4 (2012) Pages 588-607, 10.1016/j.orbis.2012.08.005.

[40] O.P. Le Maitre, O.M. Knio, Spectral Methods for Uncertainty Quantification, Series Scientific Computation, Springer, Netherlands (2010).

[41] Ley Orgánica 6/2002 del 27 de junio (Organic Law 6/2002, of 27 Juny 2002). Available at http://www. boe.es/boe/dias/2002/06/28/pdfs/ A23600-23607.pdf.

[42] F. Llera, ETA: Ejército secreto y movimiento social (ETA: secret army and social movement) in Revista de Estudios Politicos (Nueva Epoca), no 78, p 161-193 (1992).

[43] M. Martcheva, C. Castillo-Chávez, Diseases with chronic stage in a population with varying size, Mathematical Biosciences 182 (2003) $1-25$.

[44] C. Martínez, Los exilios vascos y el régimen nacionalista (The exile of the Basques and the Nationalist regime) http://www.abc.es/ hemeroteca/historico-25-07-2002/abc/Nacional/los-exiliosvascos-y-el-regimen-nacionalista_116643.html (in Spanish) 
[45] Mathematica http://www.wolfram.com/products/mathematica

[46] M. McKay, M. Meyer, Critique of and Limitations on the Use of Expert Judgements in Accident Consequence Uncertainty Analysis, Radiation Protection Dosimetry 90 (3) (2000) 325-330.

[47] J. Mena-Lorca, H.W. Hethcote, Dynamic models of infectious diseases as regulators of population sizes, Journal of Mathematical Biology 30 (1992) $693-716$.

[48] Ministerio del Interior (Spanish Ministry of Internal Affairs). Available at http://www.mir.es/DGRIS/Terrorismo_de_ETA/ultimas_ victimas/p12b-esp.htm.

[49] J. A. Nelder, R. Mead, A simplex method for function minimization, Computer Journal 7 (1964), 308-313, doi: 10.1093/comjnl/7.2.155.

[50] A. Olsson, G. Sandberg, O. Dahlblom, On Latin hypercube sampling for structural reliability analysis, Structural Safety 25 (1) (2003) 47 - 68, doi: 10.1016/S0167-4730(02)00039-5.

[51] M. Peco, Aproximacion funcional a los movimientos radicales en el ejercicio de la violencia politica politica (A Functional Approach to Radical Movements Engaged in Political Violence), Ph.D. Dissertation, UNED (2011)

[52] M. Peco, L. Peral, El conflicto de Colombia (The conflict of Colombia), Instituto de Estudios Internacionales y Europeos "Francisco de Vitoria", (2006).

[53] M. Peco, F.-J. Santonja, A.-C. Tarazona, R.-J. Villanueva, J. Villanueva-Oller, Effect of the Spanish Law of Political Parties (LPP) on the attitude of the Basque Country population towards ETA: A dynamic modelling approach, Math. Comput. Modell. 57 (2013) 16791685, doi:10.1016/j.mcm.2011.11.007.

[54] Posición Común 2003/482/PESC del Consejo, de 27 de junio de 2003, por la que se actualiza la Posición Común 2001/931/PESC sobre la aplicación de medidas específicas de lucha contra el terrorismo y se deroga la Posición Común 2003/402/PESC. (Common Position 2003/482/PESC where the Common Position 2001/931/PESC about the application of specific measures against terrorism has been updated and Common Position 2003/402/PESC is revoked). 
[55] W.H. Press, B.P. Flannery, S.A. Teukolsky, W. Vetterling, Numerical Recipes: The Art of Scientific Computing, Cambridge University Press, New York (1986).

[56] F. Reinares, Patriotas de la muerte. Por qué han militado en ETA y cuándo abandonan (Patriots of death. Why they militated in ETA and when they abandon), Ed. Taurus, Madrid (2011).

[57] J. Santillana, A mathematical model of terrorism, DRU Workshop 2011 Presentations, Disaster Resistant University Workshop: Building Partnerships in Mitigation, http://scholarworks.uno.edu/dru2011/34, (2011).

[58] J. Santillana, A system of Stochastic Difference Equations Modeling Terrorism, http://jointmathematicsmeetings.org/meetings/ national/jmm/1067-39-2089.pdf (2000).

[59] F.J. Santonja, A.C.Tarazona, R.J. Villanueva, A mathematical model of the pressure of an extreme ideology on a society, Comput. Math. Appl., 563 , pp. 836-846 (2008).

[60] Sentencia de la Sala Especial (Artículo 61 L.O.P.J.) del Tribunal Supremo, autos acumulados n. 6/2002 y 7/2002. (Sentence of the Especial Courtroom of the Supreme Court, Article 61 of the Law of Political Parties, accumulated court orders No. 6/2002 and 7/2002).

[61] L.B. Snyder, Health Communication Campaigns and Their Impact on Behavior, Journal of Nutrition Education and Behavior 39 (2, Supplement 1) (2007) S32 - S40, doi: 10.1016/j.jneb.2006.09.004.

[62] D. Stauffer, M., Sahimi, Discrete simulation of the dynamics of spread of extreme opinions in a society, Physica A: Statistical Mechanics and its Applications 364, 537 - 543 (2006), doi: 10.1016/j.physa.2005.08.040.

[63] D. Stauffer, M., Sahimi, Can a few fanatics influence the opinion of a large segment of a society?, The European Physical Journal B Condensed Matter and Complex Systems 57, 147 - 152 (2007), doi: 10.1140/epjb/e2007-00106-7.

[64] H.F. Weisberg, Nonlinear models of electoral change: the implications of political time and chaos theory for the study of mass political behavior, Electoral Studies 17 (3) (1998) 369 - 382, doi: 10.1016/S02613794(98)00033-X. 
[65] D. Xiu, Numerical Methods for Stochastic Computations: A Spectral Method Approach, Princeton University Press, New Jersey (2010).

[66] http://www.infoelectoral.mir.es/min/ (in Spanish)

[67] http://en.wikipedia.org/wiki/Basque_Country_(autonomous_ community)

[68] http://www.eustat.es/ (in Spanish)

[69] http://www.euskadi.net/q93TodoWar/elecciones JSP/ q93Contenedor . jsp? idioma=c\&menu=li_2_1_1\&opcion=menu Spanish)

[70] http://en.wikipedia.org/wiki/ETA

[71] http://www.20minutos.es/noticia/856404/0/rubalcaba/eta/ debil/ (in Spanish)

[72] http://www.libertaddigital.com/nacional/2011-06-12/ rubalcaba-bildu-tendria-menos-alcaldias-si-se-hubierahecho-de-otra-manera-1276426370/ (in Spanish)

[73] http://www.libertaddigital.com/nacional/camacho-dice-queestamos-ganando-la-batalla-a-eta-que-esta-mas-debil-quenunca-1276339356/ (in Spanish)

[74] http://www.bbc.co.uk/mundo/internacional/2010/09/100906_ eta_razones_analisis_aw.shtml (in Spanish)

[75] http://www.fmiguelangelblanco.es (in Spanish)

[76] http://en.wikipedia.org/wiki/Miguel_Angel_Blanco

[77] http://www.elmundo.es/especiales/2007/07/espana/ losmartiresdel97/album/mablanco/album_mablanco.html (in Spanish)

[78] http://es.wikipedia.org/wiki/Jose_Antonio_Ortega_Lara (in Spanish)

[79] http://www.elmundo.es/especiales/2007/07/espana/ losmartiresdel97/album/olara/album_olara.html (in Spanish)

[80] https://en.wikipedia.org/wiki/2004_Madrid_train_bombings

[81] http://scaling.imm.upv.es 